\title{
Simplified analytical models for compressed concrete columns confined by FRP and FRCM system
}

\author{
Marinella Fossetti - Gioacchino Alotta - Francesco Basone • Giuseppe Macaluso
}

Received: 3 July 2017 / Accepted: 28 October 2017

(C) RILEM 2017

\begin{abstract}
In order to consider the response of concrete columns confined by FRP and FRCM system, proper models have to be formulated. In this context the present paper shows a generalized criterion for the determination of the increase in strength, in ductility and in dissipated energy for varying corner radius ratio of the cross section and fiber volumetric ratio. The procedure is based on the best fitting of several experimental data and unlike the usual empirical approaches available in the literature, the proposed technique relates the confinement effectiveness to a single parameter representative of the relative stiffness between the original concrete core and the reinforcement system. Furthermore, the proposed analytical models overcomes the limit of many empirical or semi-empirical models given in the literature that are applicable only to specific cases. A comparison with same available models confirm the reliability of the proposed procedure.
\end{abstract}

Keywords Concrete columns - FRP and FRCM jacketing · Simplified model $\cdot$ Corner radius ratio · Fiber volumetric ratio

M. Fossetti $(\bowtie) \cdot$ G. Alotta · F. Basone - G. Macaluso Facoltà di Ingegneria e Architettura, Università degli Studi di Enna "Kore", Cittadella Universitaria, 94100 Enna, Italy

e-mail: marinella.fossetti@unikore.it

\section{Introduction}

In the recent years the need for upgrading existing structures has become increasingly popular. Indeed, an increasing number of existing reinforced concrete structures need rehabilitation or strengthening because of improper design or construction, change of the design loads, damage caused by environmental factors or seismic events. One of the most common upgrading techniques involves the use of jackets, which have the aim to increase the deformation capacity of the concrete in critical regions [1]. The use of FiberReinforced Polymers (FRP) has had an increasing popularity in the civil engineering field [2-9] for its favourable material properties: extremely high strength-to-weight ratio, corrosion resistance and ease and speed of application. Structural behavior of FRP jackets has been widely studied on the last decades and some studies have resulted in the first design guidelines of strengthened concrete [10-12]. However, some drawbacks were found: inapplicability on wet surfaces, high costs of epoxy resin and of specialized workers for application, inapplicability at temperatures lower than $10{ }^{\circ} \mathrm{C}$ or higher than $30{ }^{\circ} \mathrm{C}$.

To overcome these drawbacks, inorganic matrix systems have been introduced as a replacement for the organic systems [13-20]. The use of the fiber textiles, in conjunction with the development of new materials for the fiber, is able to ensure an adequate bond between textile and matrix. However, as a consequence of the granularity of the mortar, penetration 
and impregnation of fiber sheets are very difficult to achieve since mortars cannot wet individual fibers. Despite a lower adherence with fibers, the inorganic matrix has a number of advantages, such as full compatibility with the concrete substrate, applicability on wet surfaces and low costs of application. Although such technique has many advantages and represents a good alternative to FRP jacket, few studies have been conducted on concrete columns with the use of the Fiber Reinforced Concrete Mortar (FRCM) technique and major research has been devoted to the behavior of FRP confined concrete columns.

The combination of fiber and cementitious mortar was initially studied by Triantafillou et al. [15]. The authors compared the behaviour obtained with FRP and FRCM jacketing system of concrete specimens of equal stiffness and strength. Results showed that the use of fiber in combination with cementitious mortars provides a substantial increase in compressive strength and deformation capacity although the same specimens reinforced with FRP system showed a better gain both in terms of strength and deformation. Bournas et al. [16] studied the behaviour of reinforced concrete columns with limited capacity due to buckling of the longitudinal bars, strengthened with both reinforcement techniques. They showed a substantial gain in compressive strength and deformation capacity with a buckling delay of the longitudinal bars. Also in this case a lower effectiveness (about 10\%) of FRCM jacketing system respect to FRP case was observed. However, experimental tests carried out on full-scale columns subjected to cyclic uniaxial flexure highlighted the same effectiveness for both reinforcement techniques.

Generally, the results of earlier research conducted on the FRP and FRCM confined concrete columns suggest that the confinement effectiveness depends on several parameters: concrete strength, type of fiber and resin, fiber volume and orientation, jacket thickness and shape and corner radius of the of cross section. Many research have been devoted to the evaluation of the incidence of these parameters. Wang et al. [7] analyzed the corner radius influence and proved that no confinement is offered by flexible jackets with a zero corner radius. Rochette and Labossière [21] showed that the confinement effect is directly related to the shape of the cross section for a given number of wraps around the column. Yang et al. [22] indicated that a small corner radius can significantly reduce the ultimate strength of the FRP laminate due to the stress concentration around the corner area. Trapko [20] investigated the efficiency of Polypara-phenylenebenzo-bisthiazole (PBO) fiber bidirectional wrapped mesh, with a quantity of fiber in the direction of the wrap four times than those in the direction of the weft, embedded in an inorganic matrix in order to confine concrete cylinders. De Caso y Basolo et al. [18] studied different type of grouts as inorganic matrices along different types of fiber (unidirectional and bidirectional meshes of low-density and high-density glass fiber sheets). They found that the use of lowdensity glass fiber allowed for more effective fiber impregnation, and was the most effective reinforcement both with acrylic and hydraulic cementitious matrix; higher levels of ultimate strength are reached with the hydraulic base grout and similar levels of ultimate strain are reached in the two cases.

A large number of empirical or semi-empirical models proposed for compressed concrete columns confined by FRP and FRCM jackets has been developed. Most of these models are based on steel confinement, using the approach of Mander et al. [23] to evaluate the ultimate strength of concrete subjected to compression under constant confinement with proper adjustments to overcome the initial hypothesis of constant lateral pressure exerted on concrete. Various confinement models have been calibrated on columns wrapped by FRP and FRCM fiber sheets $[15,19,24-26]$ that usually correlate the increase of strength and ultimate strain with the confinement lateral pressure applied by the fiber sheets. Some authors have proposed confinement models where the same mathematical form is adopted for both FRP and FRCM systems but different coefficients are used in the two cases (see e.g. Triantafillou et al. [15] and Di Ludovico et al. [38]). The reliability of such models is linked to a correct definition of the effective confining pressure on the concrete member. In fact, results of several uniaxial compression tests performed on FRP and FRCM wrapped specimens have shown that the ultimate hoop strain reached in the jacket, which the maximum confining pressure depends of, is generally smaller than the ultimate strain found for flat coupon tensile tests [27-35].

In this paper an alternative approach was focused in order to link the seismic demands (strength and ductility increase) with the design parameters of the structural upgrading. Such simplified approach does not require the evaluation of the confining pressure but 
it wants provide a useful tool for the design of the structural updating to achieve certain strength and ductility values. An updated database of compression tests performed on square and circular columns wrapped by FRP and FRCM fibers was assembled from the scientific literature; from this database the parameters of the analytical laws that correlate the seismic demands in terms of strength, ductility and energy absorption and the main design parameters (corner radius, thickness jackets and type of fiber) have been defined. On the basis of this information, two different design approaches have been defined and examples of an upgrade design of columns of existing buildings were carried out.

Finally, a comparison between results obtained with the proposed approach and those obtained by the existing analytical models have been carried out; it is shown that results of the proposed approach are in good agreement with empirical and semi-empirical models available in literature.

\section{Experimental database for columns confined by FRP and FRCM system}

In this paper the data from experiments that have been performed on concrete specimens have been taken into account. The specimens have square cross section with dimension $l$ or circular cross section with diameter $l$; for the square specimens $r$ is the corner radius. All the authors used FRP and/or FRCM reinforcing laminates with unidirectional fiber, in the direction normal to the specimen axis. Only some experimental campaigns in which reinforced specimens have comparable geometric and mechanical characteristics (e.g. square and circular cross section dimension, fiber volumetric ratio, mechanical properties of fibers) have been selected in the following database, in order to define a set of homogenous experimental results. For each paper considered not all the experimental data have been considered to construct the database; this fact is due to different reasons: some specimens have rectangular cross section, while in this paper the attention is focused on square and circular cross sections in order to avoid the introduction of the effect of the proportion between two dimensions of the cross sections; some specimens have steel reinforcement, while in this papers (as in many papers) the attention is focused on not reinforced specimens; in this paper the attention is focused on specimens with a restricted range of the dimensions, in order to avoid that other effects (such as size effect) make difficult the interpretation of results; finally, only experimental results of FRP and FRCM reinforced specimens subjected to monotonic loads are considered in this paper.

In the following $\rho=2 \mathrm{r} / l$ is the corner radius ratio of the cross section. The characteristic values of stress-strain curves collected in the database are:

$f_{\text {co }}, f_{\text {cc }} \quad$ Unconfined and confined maximum compressive stress of specimens;

$\varepsilon_{\text {cou }}, \quad$ Unconfined and confined ultimate axial

$\varepsilon_{\mathrm{ccu}} \quad$ strain of specimens;

$E_{\mathrm{c}} \quad$ Elastic modulus of the unconfined specimens;

$E_{\mathrm{o}}, E \quad$ Energy absorption capacity of unconfined and confined specimens;

$\mu_{\varepsilon o}, \mu_{\varepsilon} \quad$ Unconfined and confined ductility of specimens

To estimate the $\mu_{\varepsilon \mathrm{o}}$ and $\mu_{\varepsilon}$ values, a ductility ratios of all columns were calculated similarly to Wang and $\mathrm{Wu}$ [7]. A bilinear idealization of the stress-strain curves was carried out (Fig. 1) based on the following considerations:

1. The post-yield stiffness is equal to zero.

2. The areas under the original and idealized curve within the range of interest are approximately equal (Eq. 1a).

3. The elastic stiffness of the idealized curve is calculated between 0.20 and 0.30 of the concrete strength.

4. The ultimate strain of the idealized curve is evaluated as the strain at 80 per cent of the concrete strength when the constitutive law presents a softening branch and in correspondence of maximum strength when the column failed at the peak point.

Considering the meanings of $f_{\mathrm{co}}^{*}, \varepsilon_{\mathrm{co}}^{*}$ and of $f_{\mathrm{cc}}^{*}, \varepsilon_{\mathrm{cc}}^{*}$ as shown in Fig. 1 (stress and strain at the elastic limit) and expressing $\varepsilon_{\mathrm{co}}^{*}$ and $\varepsilon_{\mathrm{cc}}^{*}$ respectively in terms of $f_{\mathrm{co}}^{*}$ and $f_{\mathrm{cc}}^{*}$, by means of Eqs. (1a) and (1b) it is possible to evaluate the values of $f_{\text {co }}^{*}$ and $f_{\text {cc }}^{*}$.

$\frac{1}{2} f_{\mathrm{co}}^{*} \varepsilon_{\mathrm{co}}^{*}+\left(\varepsilon_{\mathrm{cou}}-\varepsilon_{\mathrm{co}}^{*}\right) f_{\mathrm{co}}^{*}=E_{\mathrm{o}}$ 

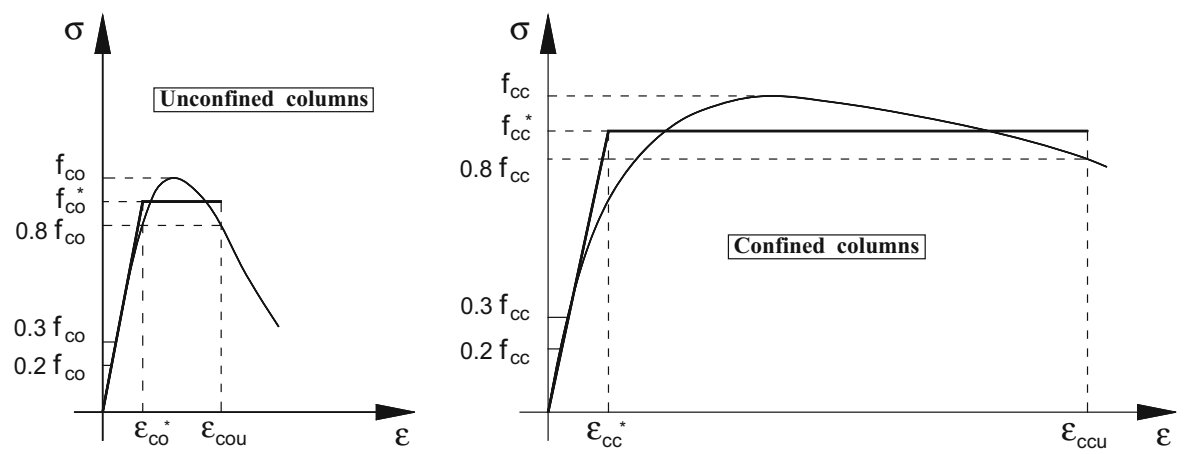

Fig. 1 Definition of the ductility ratio for unconfined and confined columns

$\frac{1}{2} f_{\mathrm{cc}}^{*} \varepsilon_{\mathrm{cc}}^{*}+\left(\varepsilon_{\mathrm{ccu}}-\varepsilon_{\mathrm{cc}}^{*}\right) f_{\mathrm{cc}}^{*}=E$

Once $f_{\mathrm{co}}^{*}$ and $f_{\mathrm{cc}}^{*}$ are evaluated it is possible to calculate the yield displacement $\varepsilon_{\mathrm{co}}^{*}, \varepsilon_{\mathrm{cc}}^{*}$ of the idealized curves and finally the ductility ratio $\mu_{\varepsilon o}=$ $\varepsilon_{\mathrm{cou}} / \varepsilon_{\mathrm{co}}^{*}$ and $\mu_{\varepsilon}=\varepsilon_{\mathrm{ccu}} / \varepsilon_{\mathrm{cc}}^{*}$ for unconfined and confined specimens.

Details and key results of the tests collected in the database for FRP and FRCM confined columns are shown in the next sections, where the symbols have the followings meanings:

$\begin{array}{ll}n & \begin{array}{l}\text { number of fiber layers; } \\ \text { nominal thickness of the reinforcing } \\ t_{\mathrm{f}}\end{array} \\ \rho_{\mathrm{f}}=4 n t_{\mathrm{f}} / & \begin{array}{l}\text { system; } \\ \text { fiber volumetric ratio; }\end{array} \\ E_{\mathrm{f}} & \text { elastic modulus of the fibers }\end{array}$

\subsection{Columns confined by FRP system}

In this section, a database has been assembled from the studies of Bournas et al. [16], Karabinis et al. [36], Rousakis et al. [35], Wang and $\mathrm{Wu}$ [7] and $\mathrm{Wu}$ and Wei [33]. Experimental results have been selected according to the criteria defined above. Key information of the tests are given in Tables 1 and 2.

\subsubsection{Bournas et al. [16]}

Bournas et al. [16] studied the behavior of prismatic concrete columns with and without internal reinforcement steel bars wrapped by FRP and FRCM (TextileReinforced Mortar-TRM in the original paper) jacketing systems. Specimens had a $200 \times 200 \mathrm{~mm}$ cross-section representing columns at approximately $2 / 3$ scale. Concrete prisms were wrapped with one and two carbon fiber layers in the longitudinal direction of the specimen. Such tests have shown that TRM jackets provide a substantial gain in compressive strength and deformation capacity by delaying buckling of the longitudinal bars; this gain increases with the volumetric ratio of the jacket. Compared with their FRP counterparts, TRM jackets used in this study was slightly less effective in increasing strength and deformation capacity by approximately $10 \%$. Tests on full-scale columns subjected to cyclic uniaxial flexure showed that TRM jacketing is very effective to increasing the cyclic deformation capacity and the energy dissipation of old RC columns.

\subsubsection{Karabinis and Rousakis [36]}

Karabinis and Rousakis [36] investigated the behaviour of concrete columns with cylindrical crosssection subjected to axial monotonic load until their failure. In such experimentation, 22 columns wrapped by carbon FRP sheets with diameter equal to $200 \mathrm{~mm}$ were considered for different levels of fiber reinforcement ratio. The authors highlighted that carbon sheets allow to considerably increase the strength and ductility of concrete as well as the energy absorption, even in low volumetric ratios.

\subsubsection{Rousakis et al. [32]}

Rousakis et al. [32] studied the behavior of FRP confined specimens subjected to cyclic axial compressive loads. An experimental campaign on 101 prismatic concrete specimens of different strength was 
Table 1 Details of FRP confined columns and key results

\begin{tabular}{|c|c|c|c|c|c|c|c|c|c|}
\hline Source & $l(\mathrm{~mm})$ & $r(\mathrm{~mm})$ & $\rho$ & $n$ & $t_{\mathrm{f}}(\mathrm{mm})$ & $\rho_{\mathrm{f}}(\%)$ & $f_{\text {co }}(\mathrm{MPa})$ & $f_{\mathrm{cc}} / f_{\mathrm{co}}$ & $E / E_{\mathrm{o}}$ \\
\hline \multirow[t]{2}{*}{ Bournas et al. [16] } & 200 & 25 & 0.25 & 2 & 0.170 & 0.680 & 15.28 & 2.00 & 4.03 \\
\hline & 200 & 25 & 0.25 & 3 & 0.170 & 1.020 & 15.28 & 2.27 & 6.77 \\
\hline \multirow[t]{12}{*}{ Karabinis et al. [36] } & 200 & - & 1.00 & 1 & 0.117 & 0.234 & 38.50 & 1.12 & 3.06 \\
\hline & 200 & - & 1.00 & 1 & 0.117 & 0.234 & 38.50 & 1.08 & 2.51 \\
\hline & 200 & - & 1.00 & 1 & 0.117 & 0.234 & 38.50 & 1.19 & 1.31 \\
\hline & 200 & - & 1.00 & 2 & 0.117 & 0.468 & 38.50 & 1.34 & 4.01 \\
\hline & 200 & - & 1.00 & 2 & 0.117 & 0.468 & 38.50 & 1.30 & 2.36 \\
\hline & 200 & - & 1.00 & 2 & 0.117 & 0.468 & 38.50 & 1.43 & 3.90 \\
\hline & 200 & - & 1.00 & 1 & 0.117 & 0.234 & 35.70 & 1.19 & 7.00 \\
\hline & 200 & - & 1.00 & 1 & 0.117 & 0.234 & 35.70 & 1.18 & 9.93 \\
\hline & 200 & - & 1.00 & 1 & 0.117 & 0.234 & 35.70 & 1.15 & 1.80 \\
\hline & 200 & - & 1.00 & 2 & 0.117 & 0.468 & 35.70 & 1.40 & 5.07 \\
\hline & 200 & - & 1.00 & 2 & 0.117 & 0.468 & 35.70 & 1.36 & 8.13 \\
\hline & 200 & - & 1.00 & 2 & 0.117 & 0.468 & 35.70 & 1.40 & 8.76 \\
\hline \multirow[t]{8}{*}{ Rousakis et al. [32] } & 200 & 30 & 0.30 & 1 & 0.117 & 0.234 & 33.04 & 1.16 & 3.39 \\
\hline & 200 & 30 & 0.30 & 1 & 0.117 & 0.234 & 33.04 & 1.17 & 2.70 \\
\hline & 200 & 30 & 0.30 & 1 & 0.117 & 0.234 & 34.20 & 1.23 & 3.81 \\
\hline & 200 & 30 & 0.30 & 1 & 0.117 & 0.234 & 34.20 & 1.23 & 6.05 \\
\hline & 200 & 30 & 0.30 & 3 & 0.138 & 0.828 & 33.04 & 1.29 & 2.92 \\
\hline & 200 & 30 & 0.30 & 3 & 0.138 & 0.828 & 33.04 & 1.27 & 2.63 \\
\hline & 200 & 30 & 0.30 & 6 & 0.138 & 1.656 & 37.97 & 1.39 & 5.33 \\
\hline & 200 & 30 & 0.30 & 6 & 0.138 & 1.656 & 37.97 & 1.38 & 5.45 \\
\hline \multirow[t]{10}{*}{ Wangand Wu [7] } & 150 & 15 & 0.20 & 1 & 0.165 & 0.440 & 31.90 & 1.05 & 3.41 \\
\hline & 150 & 30 & 0.40 & 1 & 0.165 & 0.440 & 32.30 & 1.23 & 5.24 \\
\hline & 150 & 45 & 0.60 & 1 & 0.165 & 0.440 & 30.70 & 1.43 & 5.52 \\
\hline & 150 & 60 & 0.80 & 1 & 0.165 & 0.440 & 54.10 & 1.57 & 4.64 \\
\hline & 150 & - & 1.00 & 1 & 0.165 & 0.440 & 30.90 & 1.80 & 6.76 \\
\hline & 150 & 15 & 0.20 & 2 & 0.165 & 0.880 & 31.90 & 1.32 & 6.28 \\
\hline & 150 & 30 & 0.40 & 2 & 0.165 & 0.880 & 32.30 & 1.75 & 7.42 \\
\hline & 150 & 45 & 0.60 & 2 & 0.165 & 0.880 & 30.70 & 2.22 & 9.19 \\
\hline & 150 & 60 & 0.80 & 2 & 0.165 & 0.880 & 54.10 & 2.48 & 9.53 \\
\hline & 150 & - & 1.00 & 2 & 0.165 & 0.880 & 30.90 & 2.74 & 11.39 \\
\hline \multirow[t]{2}{*}{ Wu and Wei [33] } & 150 & 30 & 0.40 & 1 & 0.167 & 0.445 & 35.30 & 1.17 & 3.84 \\
\hline & 150 & 30 & 0.40 & 2 & 0.167 & 0.891 & 35.30 & 1.71 & 10.57 \\
\hline
\end{tabular}

carried out. Each specimen had cross-section dimensions of $200 \times 200 \mathrm{~mm}$ and they were externally confined by carbon and glass FRP sheets. The results indicate that square concrete sections, properly confined by FRP reinforcement, can achieve high levels of strength and ductility. Moreover, it was found that glass FRP is less effective in terms of strength and ductility enhancement when compared with carbon FRP confinement of same axial rigidity for low volumetric ratios. Moreover, it was shown that the variation between the absorbed energy by the specimens confined with carbon and glass fibers was fairly small.

\subsubsection{Wang and $W u[7]$}

Wang and Wu [7] tested 108 carbon FRP confined short concrete columns under axial compressive loading. Experimental study was aimed to investigate the behavior of confined concrete varying the corner 
Table 2 Details of FRP confined columns for ductility ratio

\begin{tabular}{|c|c|c|c|c|c|c|c|}
\hline Source & $\rho$ & $\varepsilon_{\mathrm{cou}}(\%)$ & $\varepsilon_{\mathrm{ccu}}(\%)$ & $E\left(\mathrm{MJ} / \mathrm{m}^{3}\right)$ & $\mu_{\varepsilon}$ & $\mu_{\varepsilon o}$ & $\mu_{\varepsilon} / \mu_{\varepsilon \mathrm{o}}$ \\
\hline \multirow[t]{2}{*}{ Bournas et al. [16] } & 0.25 & 0.37 & 0.85 & 0.21 & 3.77 & 1.68 & 2.24 \\
\hline & 0.25 & 0.37 & 1.30 & 0.36 & 3.98 & 1.68 & 2.37 \\
\hline \multirow[t]{12}{*}{ Karabinis et al. [36] } & 1.00 & 0.41 & 0.70 & 0.24 & 2.20 & 2.08 & 1.06 \\
\hline & 1.00 & 0.41 & 0.95 & 0.22 & 5.45 & 2.08 & 2.63 \\
\hline & 1.00 & 0.41 & 0.59 & 0.22 & 3.51 & 2.08 & 1.69 \\
\hline & 1.00 & 0.41 & 0.75 & 0.38 & 2.78 & 2.08 & 1.34 \\
\hline & 1.00 & 0.41 & 0.58 & 0.22 & 2.84 & 2.08 & 1.37 \\
\hline & 1.00 & 0.41 & 0.73 & 0.37 & 2.74 & 2.08 & 1.32 \\
\hline & 1.00 & 0.20 & 0.86 & 0.32 & 3.96 & 1.51 & 2.62 \\
\hline & 1.00 & 0.20 & 0.84 & 0.29 & 3.56 & 1.51 & 2.36 \\
\hline & 1.00 & 0.20 & 0.30 & 0.08 & 3.02 & 1.51 & 1.99 \\
\hline & 1.00 & 0.20 & 0.60 & 0.23 & 1.63 & 1.51 & 1.08 \\
\hline & 1.00 & 0.20 & 0.78 & 0.37 & 1.74 & 1.51 & 1.15 \\
\hline & 1.00 & 0.20 & 0.80 & 0.40 & 1.70 & 1.51 & 1.12 \\
\hline \multirow[t]{8}{*}{ Rousakis et al. [32] } & 0.30 & 0.17 & 0.45 & 0.14 & 4.28 & 1.49 & 2.88 \\
\hline & 0.30 & 0.17 & 0.36 & 0.11 & 3.31 & 1.49 & 2.23 \\
\hline & 0.30 & 0.18 & 0.50 & 0.14 & 5.53 & 2.26 & 2.44 \\
\hline & 0.30 & 0.18 & 0.59 & 0.22 & 4.80 & 2.26 & 2.12 \\
\hline & 0.30 & 0.17 & 0.60 & 0.12 & 9.46 & 1.49 & 6.36 \\
\hline & 0.30 & 0.17 & 0.42 & 0.11 & 4.92 & 1.49 & 3.31 \\
\hline & 0.30 & 0.22 & 0.94 & 0.45 & 5.99 & 2.14 & 2.79 \\
\hline & 0.30 & 0.22 & 0.83 & 0.46 & 4.45 & 2.14 & 2.08 \\
\hline \multirow[t]{10}{*}{ Wang and $\mathrm{Wu}$ [7] } & 0.20 & 0.68 & 1.80 & 0.50 & 10.30 & 3.71 & 2.78 \\
\hline & 0.40 & 0.68 & 1.80 & 0.62 & 5.94 & 3.71 & 1.60 \\
\hline & 0.60 & 0.68 & 1.80 & 0.75 & 3.91 & 3.71 & 1.05 \\
\hline & 0.80 & 0.68 & 1.90 & 0.75 & 2.80 & 3.71 & 0.75 \\
\hline & 1.00 & 0.68 & 2.40 & 1.09 & 2.56 & 3.71 & 0.69 \\
\hline & 0.20 & 0.68 & 2.75 & 1.01 & 4.57 & 3.71 & 1.23 \\
\hline & 0.40 & 0.68 & 2.70 & 1.19 & 2.25 & 3.71 & 0.61 \\
\hline & 0.60 & 0.68 & 3.00 & 1.48 & 1.84 & 3.71 & 0.50 \\
\hline & 0.80 & 0.68 & 3.00 & 1.53 & 1.93 & 3.71 & 0.52 \\
\hline & 1.00 & 0.68 & 3.20 & 1.83 & 1.61 & 3.71 & 0.43 \\
\hline \multirow[t]{2}{*}{ Wu and Wei [33] } & 0.40 & 0.30 & 0.82 & 0.28 & 5.48 & 3.35 & 1.64 \\
\hline & 0.40 & 0.30 & 1.70 & 0.77 & 4.95 & 3.35 & 1.48 \\
\hline
\end{tabular}

radius, transverse stiffness of the jacket and concrete strength. These tests were performed on columns with square cross-section of $150 \times 150 \mathrm{~mm}$ and wrapped with one and two fiber layers. External reinforcement was carried out for different values of the corner radius $(15,30,45,60$ and $75 \mathrm{~mm})$. The results demonstrated that the enhancement in confined concrete strength is directly proportional to the corner radius ratio. Moreover, it was shown that the confinement provided by a jacket with sharp corners is not effective in increasing the strength of columns but effective in increasing the ductility of columns.

\subsubsection{Wu and Wei [33]}

$\mathrm{Wu}$ and Wei [33] presented the results of an experimental study on the behavior of axially loaded short rectangular columns that have been strengthened with CFRP wrap. The parameters considered were the aspect ratio, defined as the depth (longer side)/width 
(shorter side) of the cross-section, and the number of CFRP layers. All of the specimens were $300 \mathrm{~mm}$ in height with a corner radius of $30 \mathrm{~mm}$ but different cross-section aspect ratios $(1.0,1.25,1.5,1.75$, and 2.0). Experimental results showed that the strength gain in the confined concrete columns decreases with the increase of the aspect ratio and it becomes ineffective when the aspect ratio reaches 2 .

\subsection{Columns confined by FRCM system}

Several studies has been conducted on the application of carbon fiber sheets embedded in inorganic matrix for confinement of concrete columns. The first study in this field was developed by Wu and Teng [14] where small cylindrical concrete columns were tested and the inorganic matrix was found to ensure the same behavior, in terms of strength and deformability increment, as the traditional epoxy resin.

In this section, a test database was assembled from the studies of Colajanni et al. [30], Colajanni et al. [19], Ombres [34] and Triantafillou et al. [15]. Key information of the tests are given in Tables 3 and 4.

\subsubsection{Colajanni et al. [30]}

Colajanni et al. [30] studied the behavior of concrete columns wrapped with FRCM under monotonic and cyclic compressive axial loads to investigate the effect of the confinement level, the cross-section shape and the corner radius on the stiffness, strength, and ductility of FRCM confined concrete columns. The experimental test has been defined as follows: ten specimens with square cross-section with side $200 \mathrm{~mm}$; ten concrete specimens with rectangular cross-section having dimensions $200 \times 400 \mathrm{~mm}$ and ten circular cross-section specimens having diameter equal to $200 \mathrm{~mm}$. Cylindrical specimens were wrapped with two and three layers of bonded textile, while the prismatic specimens were wrapped with two and four layers. The results proved that FRCM confining jackets provide substantial gain in compressive strength, deformability and absorbed energy.

\subsubsection{Colajanni et al. [19]}

Colajanni et al. [19] tested small circular and square cross-section specimens under monotonic axial compression to evaluate the efficiency of a PBO fiber meshes embedded into an inorganic cementitious matrix. The experimental campaign was carried out in two phases: in the first one, eight cylindrical specimens with diameter and height respectively equal to 154 and $335 \mathrm{~mm}$ were tested; in the second one, seven cylindrical specimens with diameter and height respectively equal to 200 and $335 \mathrm{~mm}$ and seven specimens with square cross-section with side $200 \mathrm{~mm}$ and height of $425 \mathrm{~mm}$ were tested. For each prismatic specimen a corner radius of $20 \mathrm{~mm}$ was adopted. Experimental results showed that PBOFRCM system produced a noticeable increment in strength and ductility, though the low mechanical ratios of fiber considered were not always able to ensure hardening behavior up to rupture.

\subsubsection{Ombres [34]}

Ombres [34] evaluated the effectiveness of the confinement of cylindrical concrete specimens confined with the PBO-FRCM system varying the fibers reinforcement ratio, the fibers orientation and the compressive concrete strength. Each specimen had a diameter of the circular cross-section equal to $150 \mathrm{~mm}$ and they were wrapped with one, two, three and four layers of bonded textile. Experimental results have shown that compressive strength and ductility values of the confined specimens are influenced by number and orientation of fiber layers and the best performances were obtained when the fiber were aligned with the axis of specimens.

\subsubsection{Triantafillou et al. [15]}

Triantafillou et al. [15] studied the role of the number of textile layers and compared the confinement efficiency of systems with inorganic mortar versus epoxy resin. The investigation was carried out on: eight cylindrical specimens with a diameter of $150 \mathrm{~mm}$ and a height of $300 \mathrm{~mm}$ and six short column-type specimens with a square cross-section of $250 \times 250 \mathrm{~mm}$ and a height of $700 \mathrm{~mm}$. For each specimen a corner radius of $15 \mathrm{~mm}$ was adopted. Experimental tests proved that TRM jacketing provided a lower strength and deformability increase compared to FRP jacketing, with the exception of square columns where the same efficiency was found. Moreover, it was observed that the failure of TRM system was less abrupt compared with the FRP 
Table 3 Details of FRCM confined columns and key results

\begin{tabular}{|c|c|c|c|c|c|c|c|c|c|}
\hline Source & $l(\mathrm{~mm})$ & $r(\mathrm{~mm})$ & $\rho$ & $n$ & $t_{\mathrm{f}}(\mathrm{mm})$ & $\rho_{\mathrm{f}}(\%)$ & $f_{\text {co }}(\mathrm{MPa})$ & $\begin{array}{l}f_{\mathrm{cc}} / \\
f_{\mathrm{co}}\end{array}$ & $\begin{array}{l}E / \\
E_{0}\end{array}$ \\
\hline \multirow[t]{15}{*}{ Colajanni et al. [30] } & 200 & 15 & 0.15 & 2 & 0.047 & 0.188 & 16.48 & 1.20 & 2.62 \\
\hline & 200 & 15 & 0.15 & 2 & 0.047 & 0.188 & 16.48 & 1.16 & 2.23 \\
\hline & 200 & 30 & 0.30 & 2 & 0.047 & 0.188 & 15.90 & 1.16 & 2.51 \\
\hline & 200 & 30 & 0.30 & 2 & 0.047 & 0.188 & 15.90 & 1.18 & 2.44 \\
\hline & 200 & 15 & 0.15 & 4 & 0.047 & 0.376 & 16.48 & 1.41 & 3.24 \\
\hline & 200 & 15 & 0.15 & 4 & 0.047 & 0.376 & 16.48 & 1.54 & 4.31 \\
\hline & 200 & 30 & 0.30 & 4 & 0.047 & 0.376 & 15.90 & 1.40 & 4.26 \\
\hline & 200 & 30 & 0.30 & 4 & 0.047 & 0.376 & 15.90 & 1.48 & 5.13 \\
\hline & 200 & - & 1.00 & 2 & 0.047 & 0.188 & 16.80 & 1.24 & 5.06 \\
\hline & 200 & - & 1.00 & 2 & 0.047 & 0.188 & 16.08 & 1.28 & 5.88 \\
\hline & 200 & - & 1.00 & 3 & 0.047 & 0.282 & 16.80 & 1.41 & 5.04 \\
\hline & 200 & - & 1.00 & 3 & 0.047 & 0.282 & 16.08 & 1.49 & 4.10 \\
\hline & 200 & - & 1.00 & 2 & 0.047 & 0.188 & 16.55 & 1.24 & 4.42 \\
\hline & 200 & - & 1.00 & 3 & 0.047 & 0.282 & 16.55 & 1.48 & 5.88 \\
\hline & 200 & - & 1.00 & 3 & 0.047 & 0.282 & 16.55 & 1.44 & 5.15 \\
\hline \multirow[t]{14}{*}{ Colajanni et al. [19] } & 200 & 20 & 0.20 & 2 & 0.045 & 0.180 & 25.50 & 1.18 & 3.03 \\
\hline & 200 & 20 & 0.20 & 2 & 0.045 & 0.180 & 25.50 & 1.12 & 1.60 \\
\hline & 200 & 20 & 0.20 & 2 & 0.045 & 0.180 & 25.50 & 1.02 & 2.35 \\
\hline & 200 & 20 & 0.20 & 3 & 0.045 & 0.270 & 25.50 & 1.27 & 2.59 \\
\hline & 200 & 20 & 0.20 & 3 & 0.045 & 0.270 & 25.50 & 1.18 & 3.68 \\
\hline & 200 & 20 & 0.20 & 3 & 0.045 & 0.270 & 25.50 & 1.27 & 4.49 \\
\hline & 154 & - & 1.00 & 3 & 0.045 & 0.351 & 24.20 & 1.40 & 6.82 \\
\hline & 154 & - & 1.00 & 3 & 0.045 & 0.351 & 24.20 & 1.50 & 8.38 \\
\hline & 154 & - & 1.00 & 3 & 0.045 & 0.351 & 24.20 & 1.64 & 8.68 \\
\hline & 200 & - & 1.00 & 2 & 0.045 & 0.180 & 24.20 & 1.26 & 4.17 \\
\hline & 200 & - & 1.00 & 2 & 0.045 & 0.180 & 24.20 & 1.38 & 4.23 \\
\hline & 200 & - & 1.00 & 2 & 0.045 & 0.180 & 24.20 & 1.19 & 4.06 \\
\hline & 200 & - & 1.00 & 3 & 0.045 & 0.270 & 24.20 & 1.42 & 6.17 \\
\hline & 200 & - & 1.00 & 3 & 0.045 & 0.270 & 24.20 & 1.33 & 8.43 \\
\hline \multirow[t]{2}{*}{ Ombres [34] } & 150 & - & 1.00 & 2 & 0.046 & 0.245 & 29.26 & 1.61 & 3.83 \\
\hline & 150 & - & 1.00 & 3 & 0.046 & 0.368 & 29.26 & 1.93 & 6.21 \\
\hline \multirow[t]{2}{*}{ Triantafillou et al. [15] } & 150 & - & 1.00 & 3 & 0.047 & 0.376 & 21.81 & 1.49 & 4.89 \\
\hline & 250 & 15 & 0.12 & 4 & 0.047 & 0.301 & 14.25 & 1.51 & 3.63 \\
\hline
\end{tabular}

system, due to a slower progression of fractures of the reinforcing fibers.

In Table 3 the experimental results of compressive tests performed on square and circular cross-section concrete columns reinforced with FRCM are shown. In this paper the columns wrapped with unidirectional FRCM reinforcement perpendicular to the specimen axis have been taken into account.

\section{Proposed simplified procedure and analytical models}

The aim is to define the increase in strength $\left(f_{\mathrm{cc}} / f_{\mathrm{co}}\right)$, the increase in ductility $\left(\mu_{\varepsilon} / \mu_{\varepsilon 0}\right)$ and the increase in the dissipated energy $\left(E / E_{\mathrm{o}}\right)$ for varying $\rho$ and $\rho_{\mathrm{f}}$ in a straightforward way as function of a single parameter 
Table 4 Details of FRCM confined columns for ductility ratio

\begin{tabular}{|c|c|c|c|c|c|c|c|}
\hline Source & $\rho$ & $\varepsilon_{\text {cou }}(\%)$ & $\varepsilon_{\mathrm{ccu}}(\%)$ & $E\left(\mathrm{MJ} / \mathrm{m}^{3}\right)$ & $\mu_{\varepsilon}$ & $\mu_{\varepsilon o}$ & $\mu_{\varepsilon} / \mu_{\varepsilon \mathrm{o}}$ \\
\hline \multirow[t]{15}{*}{ Colajanni et al. [30] } & 0.15 & 0.19 & 0.73 & 0.12 & 3.41 & 1.45 & 2.35 \\
\hline & 0.15 & - & 0.62 & 0.08 & - & - & - \\
\hline & 0.30 & 0.19 & 0.68 & 0.10 & 2.95 & 1.45 & 2.03 \\
\hline & 0.30 & - & 0.55 & 0.07 & - & - & - \\
\hline & 0.15 & 0.19 & 0.83 & 0.12 & 4.16 & 1.45 & 2.86 \\
\hline & 0.15 & - & 0.79 & 0.15 & - & - & - \\
\hline & 0.30 & 0.19 & 0.87 & 0.17 & 4.91 & 1.45 & 3.38 \\
\hline & 0.30 & - & 0.73 & 0.15 & - & - & - \\
\hline & 1.00 & 0.12 & 1.31 & 0.22 & 5.95 & 3.29 & 1.81 \\
\hline & 1.00 & 0.12 & 1.50 & 0.25 & 6.77 & 3.29 & 2.06 \\
\hline & 1.00 & 0.12 & 1.53 & 0.29 & 6.96 & 3.29 & 2.12 \\
\hline & 1.00 & 0.12 & 1.28 & 0.23 & 5.28 & 3.42 & 1.55 \\
\hline & 1.00 & - & 0.87 & 0.19 & - & - & - \\
\hline & 1.00 & - & 0.99 & 0.25 & - & - & - \\
\hline & 1.00 & - & 0.88 & 0.22 & - & - & - \\
\hline \multirow[t]{14}{*}{ Colajanni et al. [19] } & 0.20 & 0.10 & 1.00 & 0.26 & 10.39 & 4.41 & 2.36 \\
\hline & 0.20 & 0.10 & 0.60 & 0.15 & 7.92 & 4.41 & 1.80 \\
\hline & 0.20 & 0.10 & 1.00 & 0.23 & 14.42 & 4.41 & 3.27 \\
\hline & 0.20 & 0.10 & 0.88 & 0.25 & 8.30 & 4.41 & 1.88 \\
\hline & 0.20 & 0.10 & 1.32 & 0.36 & 11.68 & 4.41 & 2.65 \\
\hline & 0.20 & 0.10 & 1.63 & 0.43 & 15.91 & 4.41 & 3.61 \\
\hline & 1.00 & 0.06 & 1.10 & 0.30 & 7.14 & 2.44 & 2.92 \\
\hline & 1.00 & 0.06 & 1.20 & 0.36 & 7.97 & 2.44 & 3.26 \\
\hline & 1.00 & 0.06 & 1.25 & 0.38 & 5.69 & 2.44 & 2.33 \\
\hline & 1.00 & 0.09 & 0.70 & 0.18 & 5.70 & 2.51 & 2.27 \\
\hline & 1.00 & 0.09 & 0.71 & 0.18 & 6.68 & 2.51 & 2.67 \\
\hline & 1.00 & 0.09 & 0.71 & 0.18 & 5.65 & 2.51 & 2.25 \\
\hline & 1.00 & 0.09 & 0.91 & 0.27 & 5.63 & 2.51 & 2.25 \\
\hline & 1.00 & 0.09 & 1.46 & 0.36 & 7.89 & 2.51 & 3.15 \\
\hline \multirow[t]{2}{*}{ Ombres et al. [34] } & 1.00 & 0.09 & 1.50 & 0.51 & 13.90 & 5.61 & 2.48 \\
\hline & 1.00 & 0.09 & 2.00 & 0.83 & 15.29 & 5.61 & 2.73 \\
\hline \multirow[t]{2}{*}{ Triantafillou et al. [15] } & 1.00 & 0.25 & 1.17 & 0.42 & 3.46 & 1.38 & 2.51 \\
\hline & 0.12 & 0.06 & 1.15 & 0.23 & 18.99 & 8.99 & 2.11 \\
\hline
\end{tabular}

depending on the characteristics of the original concrete core and reinforcement system.

To this purpose the following steps have been carried out:

- define a suitable parameter $\eta$ in terms of $\rho_{\mathrm{f}}$ $\left(\eta=\mathrm{f}\left(\rho_{\mathrm{f}}\right)\right)$ which depends also on the mechanical and geometrical characteristics of the system (original concrete core and FRM/FRCM jacketing). The parameter $\eta$ is defined in Eq. (2);

- collect the experimental responses for varying $\eta$ and $\rho$;
- perform the best fitting of the curves $\left(f_{\mathrm{cc}} / f_{\mathrm{co}}(\rho, \eta)\right.$; $\left.E / E_{\mathrm{o}}(\rho, \eta) ; \mu_{\varepsilon} / \mu_{\varepsilon \mathrm{o}}(\rho, \eta)\right)$ and propose an analytical law that approximate experimental results.

$\eta=\frac{\ell}{4 n t_{f}} \cdot \frac{E_{c}}{E_{f}}=\frac{E_{c}}{\rho_{f} E_{f}}$

The mathematical models for the strength, ductility and dissipated energy enhancement are obtained by a best fitting of experimental data with the least squares method. 
The coefficient of determination $\mathrm{R}^{2}$ is evaluated in order to estimate the accuracy of the regression procedure.

The models proposed in the following have two main advantages in comparison with existing models: they do not need the definition of the lateral confinement pressure in order to evaluate the strength, ductility and dissipated energy enhancement; they are obtained from data coming from different experimental campaigns, then they are able to reproduce experimental results from different authors.

Some disadvantages are also present in this approach: predictions are only accurate for systems with parameters that are included in the range of parameters of the specimens of the database selected. This fact implies that a very accurate and general model can be defined with a large number of experimental data. However, in this paper it is shown that with a not large database the definition of enhanced mechanical properties is acceptable if the parameters at hand lie in the range of those of the experimental data.

\subsection{Simplified analytical model for columns confined by FRP system}

For columns confined by FRP system, the best fitting of the experimental data leads to analytical expressions that give the increase/decrease in strength, ductility and dissipated energy as a function of the corner radius ratio and the fiber volumetric ratio as provided by Eqs. (3), (4) and (5) respectively.

$\frac{f_{\text {cc }}}{f_{\text {co }}}=3280.70 \eta^{-2.81} \rho+2.25 \eta^{-0.17}$

$\frac{\mu_{\varepsilon}}{\mu_{\varepsilon o}}=0.016 \eta^{1.18} \rho^{-8.78 \eta^{-0.79}}$

$\frac{E}{E_{\mathrm{o}}}=206.85 \eta^{-1.20} \rho+6.22 \eta^{-0.20}$

Figures 2, 3 and 4 shows respectively the value of $f_{\mathrm{cc}} / f_{\mathrm{co}}, \mu_{\mathrm{cc}} / \mu_{\mathrm{co}}$ and $E / E_{\mathrm{o}}$ for varying corner radius ratio and for three different number of fiber layers. Moreover, experimental data and coefficients of determination are shown in each figure.

A good agreement with the experimental data can be observed for the strength model. The accuracy of the ductility and the energy absorption capacity models appears worse because of the larger dispersion of these two quantities in comparison with the strength data. This is due to the fact that data are taken from different experimental campaigns and then very different stress-strain curve were considered for the construction of the database. Indeed, very different behavior of the post-elastic branch can be observed due to the different collapse mode of the reinforced specimen. This explains because a larger dispersion for the ductility and energy absorption models was obtained in comparison with the strength model. Moreover, the definition of the bilinear curve for the evaluation of the ductility is conventional; in this context it is necessary to adopt a unique method to define the bilinear curve and as a consequence the dispersion of ductility value is quite high.

General trends observed for columns confined by FRP system can be summarized in the following points:

1. the strength and the absorbed energy increase with the corner radius ratio;

2. the strength and the absorbed energy increase with the fiber volumetric ratio;

3. the ductility decreases with the corner radius ratio;

4. the ductility decreases with the fiber volumetric ratio.

\subsection{Simplified analytical model for columns confined by FRCM system}

For columns confined by FRCM system, the best fitting of the experimental data leads to analytical expressions that give the increase/decrease in strength, ductility and dissipated energy as a function of the corner radius ratio and the fiber volumetric ratio as provided by Eqs. (6), (7) and (8) respectively.

$\frac{f_{\text {cc }}}{f_{\text {co }}}=6.46 \eta^{-0.86} \rho+3.47 \eta^{-0.28}$

$\frac{\mu_{\varepsilon}}{\mu_{\varepsilon o}}=-14.19 \eta^{-1.06} \rho+14.20 \eta^{-0.43}$

$\frac{E}{E_{\mathrm{o}}}=13.41 \eta^{-0.38} \rho+118.77 \eta^{-1.01}$

Figures 5, 6 and 7 shows respectively the value of $f_{\mathrm{cc}} / f_{\mathrm{co}}, \mu_{\mathrm{cc}} / \mu_{\mathrm{co}}$ and $E / E_{\mathrm{o}}$ for varying corner radius ratio and for three different number of fiber layers.

A good agreement with the experimental data can be observed for the strength and energy absorption capacity models. The accuracy of the ductility model 
Fig. $2 f_{\text {cc }} / f_{\text {co }}-\rho$ curves of columns confined by FRP system
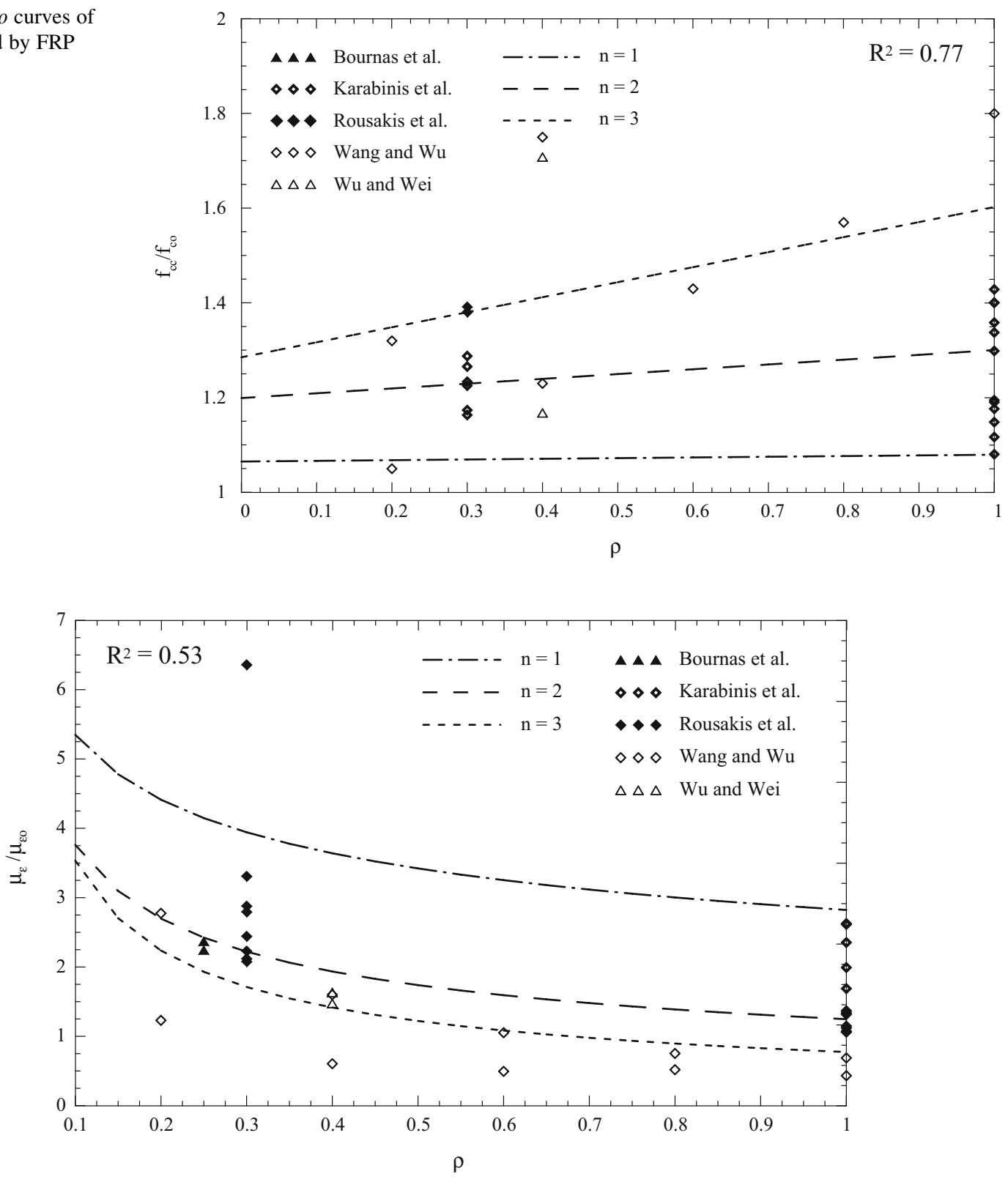

Fig. $3 \mu_{\varepsilon} / \mu_{\varepsilon o}-\rho$ curves of columns confined by FRP system

appears worse because of the larger dispersion of this quantity in comparison with the strength data. As explained in Sect. 3.1 regarding the FRP system, this is due to the fact that different experimental campaigns are taken into account in the construction of the database and then very different stress-strain curves are considered to evaluate the energy absorption and, for the evaluation of ductility, they have been bilinearized all with the same method.
General trends observed for columns confined by FRCM system can be summarized in the following points:

1. the strength and the absorbed energy increase with the corner radius ratio;

2. the strength and the absorbed energy increase with the fiber volumetric ratio;

3. the ductility decreases with the corner radius ratio; 


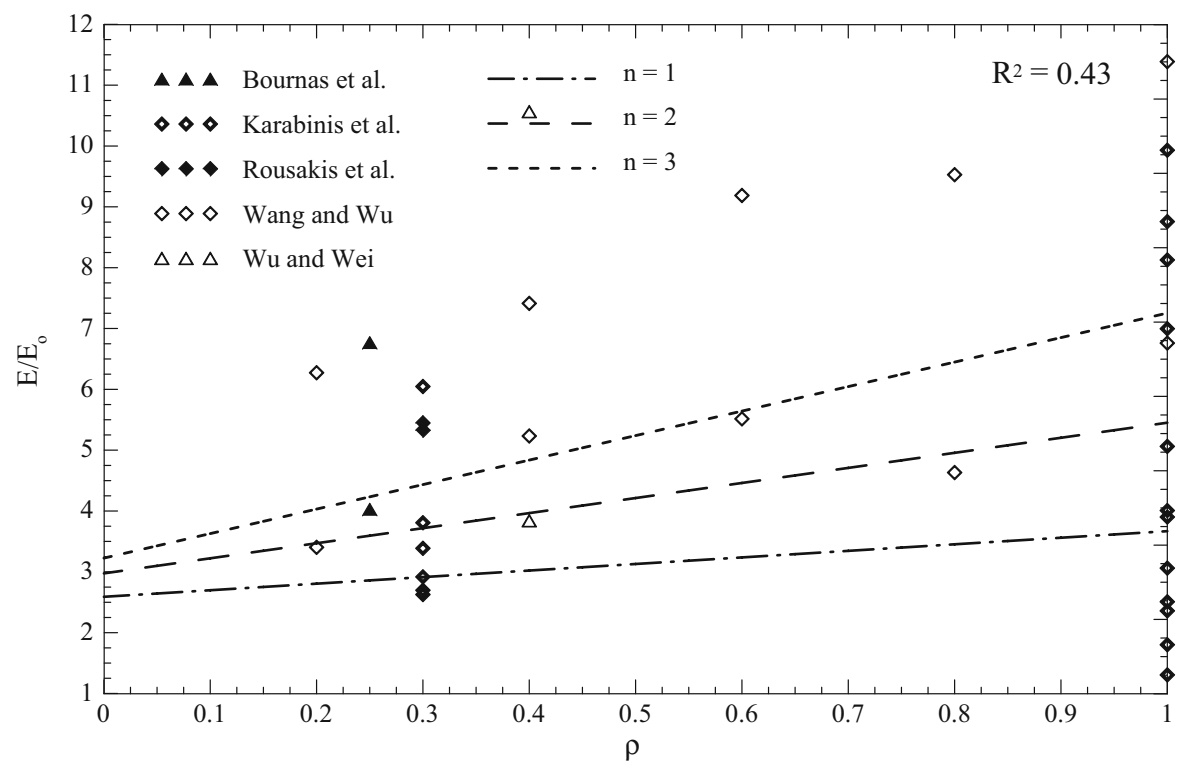

Fig. $4 E / E_{\mathrm{o}}-\rho$ curves of columns confined by FRP system

Fig. $5 f_{\text {cc }} f_{\text {co }}-\rho$ curves of columns confined by FRCM system

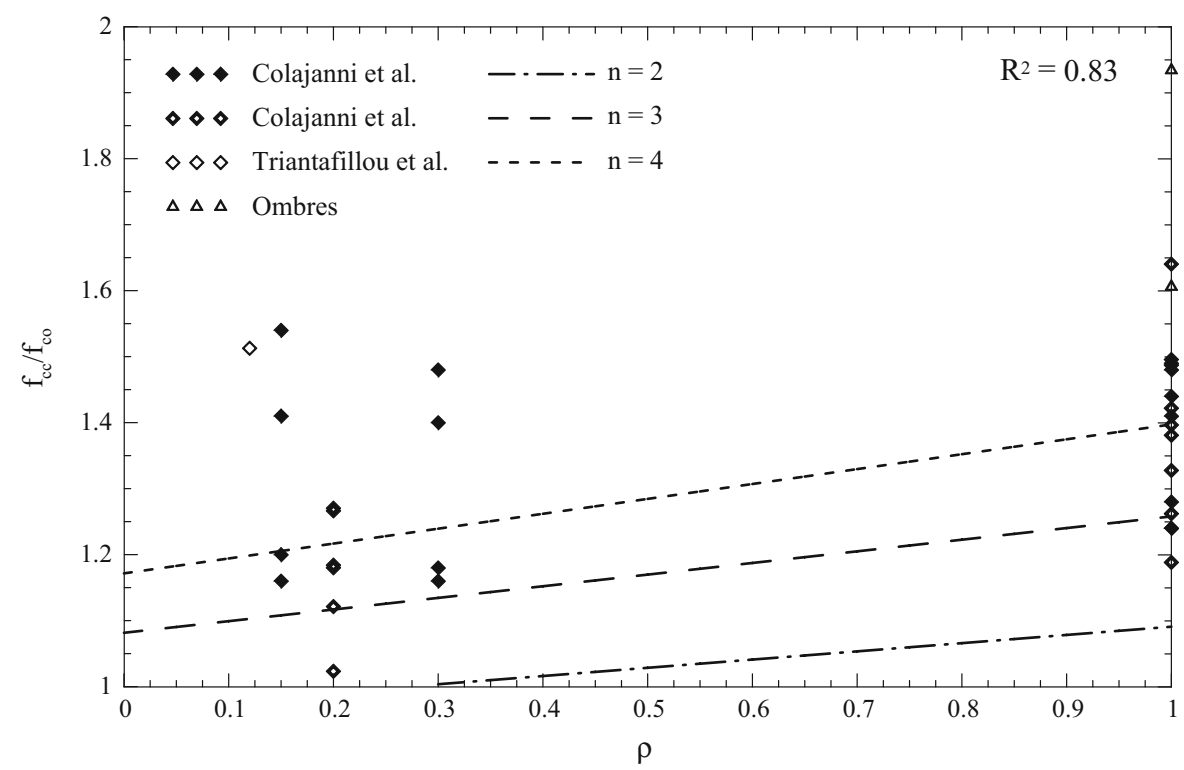

4. the ductility decreases with the fiber volumetric ratio.

\section{Applications of the proposed procedure}

In the design of the reinforcement for practical applications, two possible strategies are possible:
- Design strategy a: the increase in ductility $\left(\mu_{\varepsilon} / \mu_{\varepsilon 0}\right)$ is chosen and from it the increase in strength $\left(f_{\mathrm{cc}}\right)$ $\left.f_{\text {co }}\right)$ and the increase in dissipated energy $\left(E / E_{\mathrm{o}}\right)$ are evaluated;

- Design strategy $b$ : the increase in strength $\left(f_{\mathrm{cc}} / f_{\mathrm{co}}\right)$ is chosen and from it the increase in ductility $\left(\mu_{\varepsilon} /\right.$ $\left.\mu_{\varepsilon \mathrm{o}}\right)$ and the increase in dissipated energy $\left(E / E_{\mathrm{o}}\right)$ are evaluated. 
Fig. $6 \mu_{\varepsilon} / \mu_{\varepsilon o}-\rho$ curves of columns confined by FRCM system
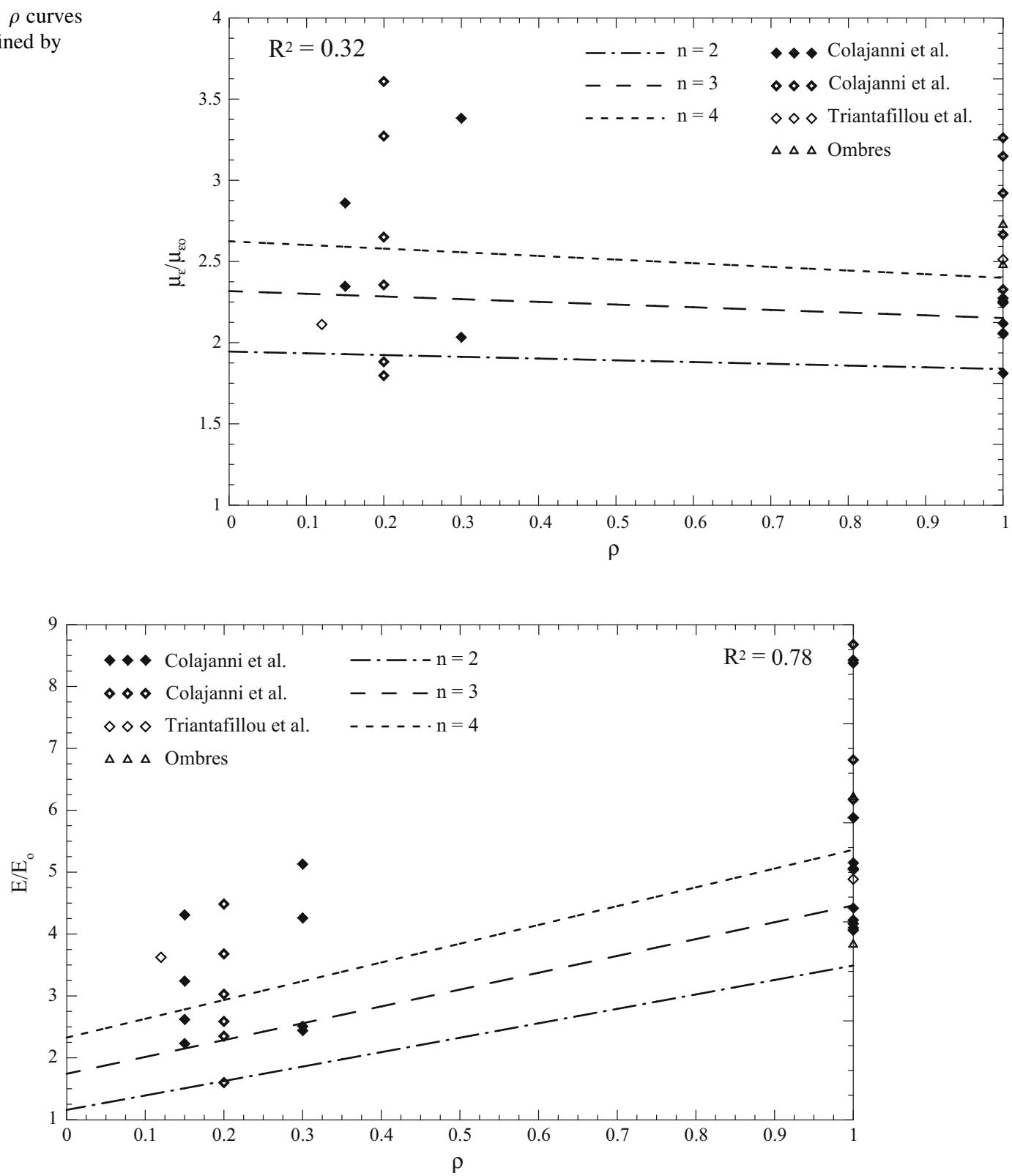

Fig. $7 E / E_{\mathrm{o}}-\rho$ curves of columns confined by FRCM system

In the reinforcement design the known parameters are: the cross section dimension $l$; elastic modulus of the unconfined specimens $E_{\mathrm{c}}$; nominal thickness of the reinforcing system $t_{\mathrm{f}}$; elastic modulus of the fibers $E_{\mathrm{f}}$.

It is observed that the value of $r$ obtained from the proposed procedure must lie in the following range: $r_{\min } \leq r \leq r_{\max }$

where

$r_{\text {min }}=20 \mathrm{~mm}$

is prescribed by [10] and

$r_{\max }=(2+\sqrt{2}) c$ 


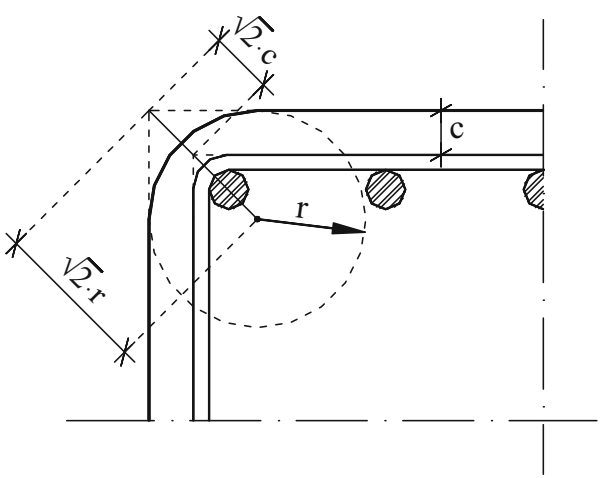

Fig. 8 Sketch of the cross section of concrete columns for the evaluation of $r_{\max }$

has been evaluated from simple geometrical considerations in Fig. 8. In particular, $r_{\max }$ is evaluated as the value corresponding to the total removal of the clear cover in correspondence of the corner of the cross section.

Both design strategies are based on the following steps. Note that some steps are labelled with the letter $a$ or $b$, if they are referred to the design "Strategy $a$ " or " $b$ " respectively.

- step 1a: $\mu_{\varepsilon} / \mu_{\varepsilon o}$ is chosen;

- step 1b: $f_{\text {cc }} / f_{\text {co }}$ is chosen;

- step 2: evaluation of the fiber volumetric ratio $\rho_{\mathrm{f}}$ and the parameter $\eta$ for different values of the number of layers $n$;

- step 3a: by means of Eq. (4) for FRP reinforced system or Eq. (7) for FRCM reinforced system the value of $\rho$ is evaluated;

- step 3b: by means Eq. (3) for FRP reinforced system or Eq. (6) for FRCM reinforced system the value of $\rho$ is evaluated;

- step 4: a check is performed on the value of $\rho$ and the inadmissible value (out of range between 0 and 1) is discarded;

- step 5: $r=\rho l / 2$ is evaluated;

- step 6: a check is performed on the value of $r$ and the inadmissible value (out the range defined in Eq. (9)) is discarded;

- step 7a: for the admissible values of $\rho$ and $r$, the value of $f_{\text {cc }} / f_{\text {co }}$ is evaluated by means of Eq. (3) for FRP reinforced system or Eq. (6) for FRCM reinforced system;

- step 7b: for the admissible values of $\rho$ and $r$, the value of $\mu_{\varepsilon} / \mu_{\varepsilon o}$ is evaluated by means of Eq. (4) for
FRP reinforced system or Eq. (7) for FRCM reinforced system;

- step 8: for the admissible values of $\rho$ and $r$, the value of $E / E_{\mathrm{o}}$ is evaluated by means of Eq. (5) for FRP reinforced system or Eq. (8) for FRCM reinforced system;

In the following two examples of the design "Strategy $a$ " and " $b$ " are reported. For the examples the given data are:

- cross section dimension $l=300 \mathrm{~mm}$;

- clear cover $c=20 \mathrm{~mm}\left(r_{\max }=68.28 \mathrm{~mm}\right)$;

- elastic modulus of the unconfined specimens $E_{\mathrm{c}}=30 \mathrm{GPa}$;

- nominal thickness of the reinforcing system $t_{\mathrm{f}}=0.117 \mathrm{~mm}$ for FRP reinforcement and $t_{\mathrm{f}}=0.047 \mathrm{~mm}$ for FRCM reinforcement;

- elastic modulus of the fibers $E_{\mathrm{f}}=240 \mathrm{GPa}$.

The example of application of "Design strategy a" was carried out for concrete columns with FRP reinforcement. The results of the performed analysis are reported in Table 5.

From the observation of Table 5 it is possible to deduct that in order to obtain the chosen ductility increase it is possible to use a fiber volumetric ratio $\rho_{\mathrm{f}}=0.31 \%$ that provides a strength increase of $22 \%$ and an energy absorption capacity increase of $261 \%$. In this case a number of fiber layers $n=2$ must be applied with a corner radius of the cross section $r=38.28 \mathrm{~mm}$. Otherwise it is possible to use a fiber volumetric ratio $\rho_{\mathrm{f}}=0.47 \%$ that provides a strength increase of $34 \%$ and an energy absorption capacity increase of $295 \%$. In this case a number of fiber layers $n=3$ must be applied with a corner radius $r=26.96 \mathrm{~mm}$.

The example of application of "Design strategy b" was carried out for concrete columns with FRCM reinforcement. The increase in strength is chosen to be $25 \%$. The results of the performed analysis are reported also in Table 5.

From the observation of Table 5, it is possible to deduct that for the chosen increase in strength the only compatible fiber volumetric ratio $\rho_{\mathrm{f}}$ is $0.25 \%$; indeed $\rho_{\mathrm{f}}=0.13 \%$ is not compatible because it gives a not acceptable value of $\rho$, while $\rho_{\mathrm{f}}=0.19 \%$ is not compatible because it gives a not acceptable value of $r$. In this case a number of fiber layers $n=4$ must be 
Table 5 Example of application of "Design strategy a" for FRP reinforcement and of "Design strategy b" for FRCM reinforcement

\begin{tabular}{|c|c|c|c|c|c|c|c|c|c|}
\hline \multirow{3}{*}{$\begin{array}{l}\text { FRP } \\
n\end{array}$} & \multirow{3}{*}{$\begin{array}{l}\text { Step 1a } \\
\text { Set } \mu_{\varepsilon} / \mu_{\varepsilon o}\end{array}$} & \multirow{2}{*}{\multicolumn{2}{|c|}{$\frac{\text { Step } 2}{\text { Evaluate }}$}} & \multirow{3}{*}{$\begin{array}{l}\text { Step 3a } \\
\text { Evaluate } \rho\end{array}$} & \multirow{3}{*}{$\begin{array}{l}\text { Step } 4 \\
\text { Check on } \rho\end{array}$} & \multirow{3}{*}{$\begin{array}{l}\text { Step } 5 \\
\text { Evaluate } r(\mathrm{~mm})\end{array}$} & \multirow{3}{*}{$\begin{array}{l}\text { Step } 6 \\
\text { Check on } r\end{array}$} & \multirow{3}{*}{$\begin{array}{l}\text { Step 7a } \\
\text { Evaluate } f_{\text {cc }} / f_{\text {co }}\end{array}$} & \multirow{3}{*}{$\begin{array}{l}\text { Step } 8 \\
\text { Evaluate } E / E_{\mathrm{o}}\end{array}$} \\
\hline & & & & & & & & & \\
\hline & & $\rho_{\mathrm{f}}(\%)$ & $\eta$ & & & & & & \\
\hline \multicolumn{10}{|c|}{ Design strategy a } \\
\hline 1 & 2.40 & 0.16 & 80.13 & 1.79 & Unusable & - & - & - & - \\
\hline 2 & 2.40 & 0.31 & 40.06 & 0.26 & Usable & 38.28 & Usable & 1.22 & 3.61 \\
\hline 3 & 2.40 & 0.47 & 26.71 & 0.18 & Usable & 26.96 & Usable & 1.34 & 3.95 \\
\hline \multirow{3}{*}{$\begin{array}{l}\text { FRCM } \\
n\end{array}$} & Step 1b & \multicolumn{2}{|l|}{ Step 2} & \multirow{3}{*}{$\begin{array}{l}\text { Step } 3 b \\
\text { Evaluate } \rho\end{array}$} & \multirow{3}{*}{$\begin{array}{l}\text { Step } 4 \\
\text { Check on } \rho\end{array}$} & \multirow{3}{*}{$\begin{array}{l}\text { Step } 5 \\
\text { Evaluate } r(\mathrm{~mm})\end{array}$} & \multirow{3}{*}{$\begin{array}{l}\text { Step } 6 \\
\text { Check on } r\end{array}$} & \multirow{3}{*}{$\begin{array}{l}\text { Step } 7 \mathrm{~b} \\
\text { Evaluate } \mu_{\varepsilon} / \mu_{\varepsilon o}\end{array}$} & \multirow{3}{*}{$\begin{array}{l}\text { Step } 8 \\
\text { Evaluate } E / E_{\mathrm{o}}\end{array}$} \\
\hline & Set $f_{\mathrm{cc}} / f_{\mathrm{co}}$ & Evaluat & & & & & & & \\
\hline & & $\rho_{\mathrm{f}}(\%)$ & $\eta$ & & & & & & \\
\hline \multicolumn{10}{|c|}{ Design strategy $b$} \\
\hline 2 & 1.25 & 0.13 & 99.73 & 2.28 & Unusable & - & - & - & - \\
\hline 3 & 1.25 & 0.19 & 66.49 & 0.96 & Usable & 143.30 & Unusable & - & - \\
\hline 4 & 1.25 & 0.25 & 49.87 & 0.35 & Usable & 52.11 & Usable & 2.55 & 3.38 \\
\hline
\end{tabular}

applied with a corner radius of the cross section $r=52.11 \mathrm{~mm}$.

\section{Comparison with some available models}

In this section comparisons are made between the strength enhancement deduced by the proposed model in Sect. 3 and that deducted from existing analytical expressions.

Generally, the confinement effect in terms of strength is related to the effective lateral confinement pressure $\left(f_{1, \mathrm{e}}\right)$ by the following expression:

$\frac{f_{\mathrm{cc}}}{f_{\mathrm{co}}}=\alpha+k_{1}\left(\frac{f_{1, \mathrm{e}}}{f_{\mathrm{co}}}\right)^{m}$

where $\alpha, k_{1}$ e $\mathrm{m}$ are non-dimensional parameters experimentally evaluated. The reduced effectiveness provided by jackets other than resins-impregnated ones may be taken into account by splitting $k_{1}$ as follows:

$k_{1}=\alpha k_{1, R}$

where $\alpha$ is an effectiveness coefficient which depend of the specifying jacketing system and $k_{1, \mathrm{R}}$ is the nondimensional parameter calibrated for specimens wrapped by FRP system.
The effective lateral confinement pressure can be evaluated by the following expression:

$f_{\mathrm{l}, \mathrm{e}}=\frac{1}{2} \rho_{\mathrm{f}} E_{\mathrm{f}} \varepsilon_{\mathrm{f}} k_{\mathrm{e}}$

where $E_{\mathrm{f}}$ and $\varepsilon_{\mathrm{f}}$ are the elastic modulus and strain of the jackets in the lateral direction, respectively, $k_{\mathrm{e}}$ is the effectiveness coefficient that takes into account the variation of the confinement pressure in square and rectangular cross-section specimens respect to circular ones, close to the corners. Such coefficient is provided by the authors of each confinement model.

Various models were considered in order to predict the strength enhancement respectively of FRP and FRCM confined specimens.

In particular, Italian CNR-DT200 Guidelines [10] provides a confinement model for concrete columns wrapped by FRP jacket as follows:

$\frac{f_{\mathrm{cc}}}{f_{\mathrm{co}}}=1+2.6\left(\frac{f_{1, \mathrm{e}}}{f_{\mathrm{co}}}\right)^{2 / 3}$

CNR [10] defined the effectiveness coefficient as follows:

$k_{\mathrm{e}}=k_{\mathrm{H}} k_{\mathrm{v}} k_{\alpha}$

where $k_{\mathrm{H}}$ is the horizontal effectiveness coefficient, $k_{\mathrm{v}}$ is the vertical effectiveness coefficient and $k_{\alpha}$ is the 
effectiveness coefficient which takes into account the inclination of the reinforcement fibers. Horizontal effectiveness coefficient can be expressed as:

$k_{\mathrm{H}}=1-\frac{2(\ell-r)^{2}}{3 A_{g}}$

where $A_{g}$ represents the cross section area of the specimen. For continuous jackets with fibers in the direction perpendicular to the member axis $k_{\mathrm{v}}$ and $k_{\alpha}$ are equal to 1 .

Triantafillou et al. [15] proposed the following expressions for concrete columns reinforced with resin (18a) and mortar (18b) impregnated fibers, respectively:

$\frac{f_{c c}}{f_{c o}}=1+2.79 \frac{f_{l, e}}{f_{c o}}$

$\frac{f_{c c}}{f_{c o}}=1+1.90 \frac{f_{l, e}}{f_{c o}}$

Furthermore, the effectiveness coefficient is defined as in Eq. (16).

Colajanni et al. [19] used the confinement model of Spoelstra and Monti [37] to evaluate the strength gain provided by FRCM jacket

$\frac{f_{\mathrm{cc}}}{f_{\mathrm{co}}}=2.254 \sqrt{1+7.94 \frac{f_{\mathrm{l}, \mathrm{e}}}{f_{\mathrm{co}}}}-2 \frac{f_{\mathrm{l, \textrm {e }}}}{f_{\mathrm{co}}}-1.254$

Campione et al. [25] provided the lateral confinement pressure as follows:

$f_{l}=\frac{2 n t_{f} f_{r}}{l}$

where $f_{r}$ is equal to:

$f_{r}=f_{f u}\left[\left(1-\frac{\sqrt{2}}{2} k_{i}\right) \frac{2 r}{l}+k_{i} \frac{\sqrt{2}}{2}\right]$

in which $f_{\text {fu }}$ is the ultimate strength of the fiber and $k_{\mathrm{i}}$ a coefficient experimentally calibrated and equal to 0.2121 . The authors defined the effectiveness coefficient equal to $1 / 3$ for square cross-section specimens. The confinement model proposed by Campione et al. [25] for FRP reinforced columns is defined as:

$\frac{f_{\mathrm{cc}}}{f_{\mathrm{co}}}=1+2 \frac{f_{\mathrm{l}, \mathrm{e}}}{f_{\mathrm{co}}}$

Pellegrino et al. [24] proposed an analytical model for FRP confinement of concrete columns with and without internal steel reinforcement. The non-dimensional coefficient $k_{1}$ is defined as follows:

$k_{1}=k_{A} k_{R}$

$k_{\mathrm{A}}$ is evaluated as:

$k_{A}=A\left(\frac{f_{1, \mathrm{e}}}{f_{\mathrm{co}}}\right)^{-\alpha}$

where $A$ and $\alpha$ are two non-dimensional parameters experimentally calibrated for concrete specimens reinforced by FRP jackets. The authors provided the values of such coefficients for specimens without reinforcing bars equal to $A=2.25$ and $\alpha=-0.25$. $\mathrm{k}_{\mathrm{R}}$ is provided by the following expression:

$\begin{cases}1-2.5(0.3-2 r / l) & \text { if } 2 r / \ell<0.3 \\ 1 & \text { if } 2 r / \ell \geq 0.3\end{cases}$

Mirmiran et al. [5] defined an analytical model for FRP jackets where the coefficient $k_{1}$ is evaluated by the following expression:

$k_{1}=6.0\left(f_{l, e}\right)^{-0.30}$

and the effectiveness coefficient as $k_{e}=2 r / \ell$.

Di Ludovico et al. [38] assumed $m=1$ and the coefficient $k_{1}$ for specimens reinforced with resin and mortar impregnated fibers equal respectively to 2.94 and 3.45 .

Ombres [34] proposed the following expression for concrete columns confined with PBO-FRCM system:

$\frac{f_{\mathrm{cc}}}{f_{\mathrm{co}}}=1+5.268 \frac{f_{1, \mathrm{e}}}{f_{\mathrm{co}}}$

Furthermore, the authors assumed a mean value of the effectiveness coefficient equal to 0.492 .

De Caso y Basolo et al. [18] proposed a semiempirical model for columns reinforced with FRCM system. They assumed the coefficients $\mathrm{m}$ and $k_{1}$ equal respectively to 1 and 3.34 .

The strength increase $f_{\text {cc }} / f_{\text {co }}$ has been evaluated for each confinement model considered respectively for concrete specimens reinforced with FRP and FRCM systems. For this comparison, concrete columns with square and circular cross-section for different values of the corner radius ratio, fiber volumetric ratio and unconfined maximum compressive strength have been considered. Furthermore, two various types of fibers respectively for FRP and FRCM jacketing systems are considered. Mechanical properties of the fibers are 
synthesized in Table 6. For both reinforcement techniques it can be observed that fibers \#1 present lower tensile strengths and ultimate deformation capacity respect to fibers \#2. The comparisons between proposed and existing models are summarized in Tables 7 and 8 for FRP and FRCM systems, respectively.

For both reinforcement techniques, the strength predictions of the proposed model are more conservative respect to those obtained from the confinement model presented above. As can be observed, the models of Campione et al. [25], Pellegrino et al. [24] and Mirmiran et al. [5] gives results closer to the proposed model for FRP jacketing system, although the other confinement models considered in this comparison provide acceptable results.

For FRCM system, a good agreement of the strength prediction can be observed with the model of Triantafillou et al. [15], where two different confinement models for FRP and FRCM system are provided. However, a larger differences for FRCM system can be observed between the existing confinement models and the proposed model in this paper. In particular, high values of strength are obtained with the confinement model of Ombres [34].

The strength enhancement predictions of the proposed model are more closer to the predictions of existing models for lower strength fiber (fiber \#1). This fact is more evident for FRP systems respect to FRCM systems, probably because the FRCM systems provide a lower effectiveness in terms of strength respect to FRP systems

For FRP and FRCM system, a more accurate prediction is achieved for high values of concrete compressive strength. Such consideration is obviously due to the fact that for high values of concrete compressive strength, the strength gain offers by external reinforcement decreases.

Moreover, for FRCM system, when $\rho$ is equal to 1.0 the difference between the proposed model and the available models is higher than those observed for lower values of $\rho$. This fact is mainly related on the dispersion of the collected data in correspondence of $\rho=1.0$.

No comparisons are made with ductility and energy absorption capacity enhancement predictions because the existing models does not provide these information. In some cases, the ultimate strain increase is provided but the "yield" strain, necessary to define the ductility, is not provided, while in this approach the ductility is readily evaluated once the bilinear idealization of the stress-strain curve is performed.

Finally it should be pointed out that the cross section dimensions of the specimens considered in this paper are quite homogeneous. Indeed, very similar dimensions are considered in the experimental tests; most of these consider dimensions of the cross section equal to $200 \mathrm{~mm}$ and $150 \mathrm{~mm}$ (or $154 \mathrm{~mm}$ ) and they are always less than $250 \mathrm{~mm}$. On the other hand, it is well known that the size effects are relevant for the concrete and for future experimental investigations should be carried out in order to account such effects.

Generally, the accuracy of the confinement models adopted in literature is strongly correlated with the correct definition of the effective confinement pressure and the effectiveness coefficient, especially when the reduced effectiveness provided by jackets other than resins-impregnated ones must be taken into account. The proposed model overcome these drawbacks and at the same time provides a simplified model for an immediate estimate of the strength and ductility increase of the concrete columns.

Table 6 Mechanical properties of reinforcing fibers for specimens reinforced with FRP and FRCM systems

\begin{tabular}{|c|c|c|c|c|c|}
\hline Type of fiber & Nominal thickness (mm) & $\begin{array}{l}\text { Ultimate tensile } \\
\text { strength (MPa) }\end{array}$ & $\begin{array}{l}\text { Ultimate tensile } \\
\text { strain }(\%)\end{array}$ & Elastic modulus (GPa) & $\begin{array}{l}\text { Primary fiber } \\
\text { direction }\end{array}$ \\
\hline \multicolumn{6}{|c|}{ FRP jacketing system } \\
\hline$\# 1$ & 0.117 & 3700 & 1.54 & 240 & Unidirectional \\
\hline$\# 2$ & 0.165 & 4364 & 2.00 & 219 & Unidirectional \\
\hline \multicolumn{6}{|c|}{ FRCM jacketing system } \\
\hline$\# 1$ & 0.047 & 4800 & 2.00 & 240 & Unidirectional \\
\hline$\# 2$ & 0.045 & 5800 & 2.15 & 270 & Unidirectional \\
\hline
\end{tabular}


Table 7 Experimental and predicted strength of FRP confined specimens

\begin{tabular}{|c|c|c|c|c|c|c|c|c|c|c|c|c|c|c|c|c|c|}
\hline \multirow[t]{3}{*}{$l(\mathrm{~m})$} & \multirow[t]{3}{*}{$\rho$} & \multirow[t]{3}{*}{$\rho_{\mathrm{f}}(\%)$} & \multirow[t]{3}{*}{$f_{\text {co }}(\mathrm{MPa})$} & \multirow{2}{*}{\multicolumn{2}{|c|}{$\begin{array}{l}\text { Proposed } \\
\text { model } \\
f_{\mathrm{cc}} / f_{\mathrm{co}}\end{array}$}} & \multirow{2}{*}{\multicolumn{2}{|c|}{$\begin{array}{l}\text { CNR- } \\
\text { DT200 } \\
{[10]} \\
f_{\mathrm{cc}} / f_{\mathrm{co}}\end{array}$}} & \multirow{2}{*}{\multicolumn{2}{|c|}{$\begin{array}{l}\text { Triantafillou } \\
\text { et al. [15] } \\
f_{\mathrm{cc}} / f_{\text {co }}\end{array}$}} & \multirow{2}{*}{\multicolumn{2}{|c|}{$\begin{array}{l}\text { Campione } \\
\text { et al. [25] } \\
f_{\text {cc }} / f_{\text {co }}\end{array}$}} & \multirow{2}{*}{\multicolumn{2}{|c|}{$\begin{array}{l}\text { Pellegrino } \\
\text { et al. [24] } \\
f_{\text {cc }} / f_{\text {co }}\end{array}$}} & \multirow{2}{*}{\multicolumn{2}{|c|}{$\begin{array}{l}\text { Mirmiran } \\
\text { et al. [5] } \\
f_{\text {cc }} / f_{\text {co }}\end{array}$}} & \multirow{2}{*}{\multicolumn{2}{|c|}{$\begin{array}{l}\text { Di } \\
\text { Ludovico } \\
\text { et al. [38] } \\
f_{\text {cc }} / f_{\text {co }}\end{array}$}} \\
\hline & & & & & & & & & & & & & & & & & \\
\hline & & & & $\# 1$ & $\# 2$ & $\# 1$ & $\# 2$ & $\# 1$ & $\# 2$ & $\# 1$ & $\# 2$ & $\# 1$ & $\# 2$ & $\# 1$ & $\# 2$ & $\# 1$ & $\# 2$ \\
\hline 300 & 0.13 & 156 & 20 & & 1.12 & 1.45 & 1.63 & & 1.34 & 1.03 & 1.04 & 1.05 & 1.09 & 1.08 & 1.12 & 1.21 & 1.35 \\
\hline 300 & 0.13 & .312 & 20 & 1.21 & 1.28 & 1.71 & 2.01 & 1.40 & 1.67 & 1.05 & 1.08 & 1.12 & 1.22 & 1.14 & 1.20 & 1.42 & 1.71 \\
\hline 300 & 0.13 & 0.468 & 20 & 1.33 & 1.43 & 1.94 & 2.32 & 1.60 & 2.01 & 1.08 & 1.13 & 1.19 & 1.37 & 1.18 & 1.26 & 1.63 & 2.06 \\
\hline 300 & 0.17 & .156 & 20 & 1.07 & 1.12 & 1.47 & 1.67 & 1.22 & 1.36 & 1.03 & 1.05 & 1.06 & 1.12 & 1.10 & 1.15 & 1.23 & 1.38 \\
\hline 300 & 0.17 & 312 & 20 & 1.22 & 1.29 & 1.75 & 2.06 & 1.43 & 1.72 & 1.06 & 1.09 & 1.15 & 1.28 & 1.17 & 1.24 & 1.46 & 1.76 \\
\hline 300 & 0.17 & 0.468 & 20 & 1.34 & 1.45 & 1.98 & 2.38 & 1.65 & 2.08 & 1.08 & 1.14 & 1.24 & 1.46 & 1.23 & 1.32 & 1.68 & 2.14 \\
\hline 300 & 0.13 & 156 & 25 & 1.06 & 1.11 & 1.39 & 1.55 & 1.16 & 1.27 & 1.02 & 1.03 & 1.04 & 1.07 & 1.07 & 1.10 & & 1.28 \\
\hline 300 & 0.13 & 312 & 25 & 1.20 & 1.27 & 1.62 & 1.87 & 1.32 & 1.54 & 1.04 & 1.07 & 1.09 & 1.17 & 1.11 & 1.16 & 1.34 & 1.57 \\
\hline 300 & 0.13 & 0.468 & 25 & 1.31 & 1.41 & 1.81 & 2.14 & 1.48 & 1.81 & 1.06 & 1.10 & 1.15 & 1.28 & 1.14 & 1.21 & & 1.85 \\
\hline 300 & 0.17 & .156 & & 1.06 & 1.11 & 1.41 & 1.57 & 1.17 & 1.29 & 1.02 & 1.04 & 1.05 & 1.09 & 1.08 & 1.12 & & 1.30 \\
\hline 300 & 0.17 & 312 & 25 & 1.20 & 1.27 & 1.65 & 1.9 & 1.35 & 1.5 & 1.04 & 1.07 & 1.11 & 1.21 & 1.14 & 1.20 & 1.3 & 1.61 \\
\hline 300 & 0.17 & 0.468 & 25 & 1.32 & 1.42 & 1.85 & 2.19 & 1.52 & 1.87 & 1.07 & 1.11 & 1.18 & 1.35 & 1.18 & 1.26 & 15 & 1.91 \\
\hline 300 & 0.13 & .156 & 30 & 1.05 & 1.10 & 1.34 & 1.48 & 1.13 & 1.22 & 1.02 & 1.03 & 1.03 & 1.06 & 1.06 & 1.08 & 1.14 & 1.24 \\
\hline 300 & 0.13 & 312 & 30 & 1.19 & 1.25 & 1.54 & 1.77 & 1.27 & 1.45 & 1.03 & 1.06 & 1.07 & 1.13 & 1.09 & 1.13 & & 1.47 \\
\hline 300 & 0.13 & 0.468 & 30 & 1.30 & 1.39 & 1.71 & 2.01 & 1.40 & 1.67 & 1.05 & 1.08 & 1.12 & 1.22 & 1.12 & 1.17 & 1.42 & 1.71 \\
\hline 300 & 0.17 & 0.156 & 30 & 1.05 & 1.10 & 1.36 & 1.51 & 1.14 & 1.24 & 1.02 & 1.03 & 1.04 & 1.07 & 1.07 & 1.10 & & 1.25 \\
\hline 300 & 0.17 & 0.312 & 30 & 1.19 & 1.26 & 1.57 & 1.81 & 1.29 & 1.48 & 1.04 & 1.06 & 1.09 & 1.17 & 1.11 & 1.16 & 1.30 & 1.51 \\
\hline 300 & 0.17 & 0.468 & 30 & 1.31 & 1.40 & 1.75 & 2.06 & 1.43 & 1.72 & 1.06 & 1.09 & 1.15 & 1.28 & 1.15 & 1.22 & 1.46 & 1.76 \\
\hline 300 & 1.00 & 0.156 & 20 & & 1.14 & 1.71 & 2.01 & 1.40 & 1.67 & 1.29 & 1.48 & 1.20 & 1.38 & 1.63 & 1.90 & & 1.71 \\
\hline 300 & 1.00 & 0.312 & 20 & 1.30 & 1.46 & 2.13 & 2.60 & 1.80 & 2.34 & 1.58 & 1.96 & 1.48 & 1.90 & 2.02 & 2.47 & 1.85 & 2.42 \\
\hline 300 & 1.00 & 0.468 & 20 & 1.60 & 1.99 & 2.49 & 3.09 & 2.21 & 3.02 & 1.86 & 2.45 & 1.79 & 2.50 & 2.36 & 2.95 & 2.27 & 3.12 \\
\hline 300 & 1.00 & 0.156 & 25 & 1.07 & 1.13 & 1.62 & 1.87 & 1.32 & 1.54 & 1.23 & 1.39 & 1.15 & 1.29 & 1.50 & 1.72 & 1.34 & 1.57 \\
\hline 300 & 1.00 & 0.312 & 25 & 1.28 & 1.42 & 1.98 & 2.38 & 1.64 & 2.08 & 1.46 & 1.77 & 1.36 & 1.68 & 1.82 & 2.17 & 1.68 & 2.13 \\
\hline 300 & 1.00 & 0.468 & 25 & 1.55 & 1.89 & 2.28 & 2.80 & 1.97 & 2.61 & 1.69 & 2.16 & 1.60 & 2.13 & 2.09 & 2.56 & 2.02 & 2.70 \\
\hline 300 & 1.00 & 0.156 & 30 & 1.06 & 1.12 & 1.55 & 1.77 & 1.27 & 1.45 & 1.19 & 1.32 & 1.12 & 1.23 & 1.42 & 1.60 & 1.28 & 1.47 \\
\hline 300 & 1.00 & 0.312 & 30 & 1.26 & 1.39 & 1.87 & 2.22 & 1.54 & 1.90 & 1.38 & 1.64 & 1.29 & 1.54 & 1.68 & 1.98 & 1.57 & 1.94 \\
\hline 300 & 1.00 & 0.468 & 30 & & 1.82 & 2.13 & 2.60 & 1.80 & 2.34 & 1.58 & 1.96 & 1.48 & 1.90 & 1.91 & 2.30 & 1.85 & 2.42 \\
\hline
\end{tabular}

\section{Conclusions}

In this paper the effects of FRP and FRCM jacketing on compressed square or circular concrete columns have been discussed. A simplified analytical model for the identification of the increase in strength, in ductility and in dissipated energy for varying corner radius ratio of the cross section and fiber volumetric ratio has been proposed. From the best fitting of experimental data some analytical functions for the practical evaluation of the confinement effectiveness have been provided.

Since the analytical functions obtained from the best fitting approximate several experimental results, they can be used for each kind of FRM and FRCM jacketing, overcoming the limit of many empirical or semi-empirical models given in the literature, that are affected by experimental calibration on specific 
Table 8 Experimental and predicted strength of FRCM confined specimens

\begin{tabular}{|c|c|c|c|c|c|c|c|c|c|c|c|c|c|c|c|}
\hline \multirow[t]{3}{*}{$l(\mathrm{~mm})$} & \multirow[t]{3}{*}{$\rho$} & \multirow[t]{3}{*}{$\rho_{\mathrm{f}}(\%)$} & \multirow[t]{3}{*}{$f_{\text {co }}(\mathrm{MPa})$} & \multirow{2}{*}{\multicolumn{2}{|c|}{$\begin{array}{l}\begin{array}{l}\text { Proposed } \\
\text { model }\end{array} \\
f_{\mathrm{cc}} / f_{\mathrm{co}}\end{array}$}} & \multirow{2}{*}{\multicolumn{2}{|c|}{$\begin{array}{l}\text { Triantafillou } \\
\text { et al. [15] } \\
\frac{f_{\mathrm{cc}} / f_{\text {co }}}{}\end{array}$}} & \multirow{2}{*}{\multicolumn{2}{|c|}{$\begin{array}{l}\text { Colajanni } \\
\text { et al. [19] } \\
\frac{f_{\text {cc }} / f_{\text {co }}}{}\end{array}$}} & \multirow{2}{*}{\multicolumn{2}{|c|}{$\begin{array}{l}\text { De Caso } \\
\text { et al. [18] } \\
f_{\text {cc }} / f_{\text {co }}\end{array}$}} & \multirow{2}{*}{\multicolumn{2}{|c|}{$\begin{array}{l}\text { Di Ludovico } \\
\text { et al. [38] } \\
\frac{f_{\mathrm{cc}} / f_{\mathrm{co}}}{}\end{array}$}} & \multirow{2}{*}{\multicolumn{2}{|c|}{$\begin{array}{l}\text { Ombres } \\
\frac{[34]}{f_{\mathrm{cc}} / f_{\mathrm{co}}}\end{array}$}} \\
\hline & & & & & & & & & & & & & & & \\
\hline & & & & $\# 1$ & $\# 2$ & $\# 1$ & $\# 2$ & $\# 1$ & $\# 2$ & $\# 1$ & $\# 2$ & $\# 1$ & $\# 2$ & $\# 1$ & $\# 2$ \\
\hline 300 & 0.13 & 0.125 & 20 & 0.98 & 1.00 & 1.14 & 1.17 & 1.44 & 1.50 & 1.50 & 1.58 & 1.26 & 1.30 & 1.78 & 1.90 \\
\hline 300 & 0.13 & 0.188 & 20 & 1.11 & 1.13 & 1.21 & 1.25 & 1.62 & 1.70 & 1.75 & 1.87 & 1.39 & 1.45 & 2.17 & 2.35 \\
\hline 300 & 0.13 & 0.251 & 20 & 1.20 & 1.23 & 1.29 & 1.33 & 1.78 & 1.88 & 2.00 & 2.16 & 1.52 & 1.60 & 2.56 & 2.81 \\
\hline 300 & 0.17 & 0.125 & 20 & 0.99 & 1.01 & 1.15 & 1.18 & 1.47 & 1.53 & 1.50 & 1.58 & 1.28 & 1.35 & 1.78 & 1.90 \\
\hline 300 & 0.17 & 0.188 & 20 & 1.11 & 1.14 & 1.23 & 1.27 & 1.66 & 1.74 & 1.75 & 1.87 & 1.42 & 1.48 & 2.17 & 2.35 \\
\hline 300 & 0.17 & 0.251 & 20 & 1.21 & 1.24 & 1.31 & 1.36 & 1.83 & 1.93 & 2.00 & 2.16 & 1.56 & 1.65 & 2.56 & 2.81 \\
\hline 300 & 0.13 & 0.125 & 25 & 0.97 & 0.99 & 1.11 & 1.13 & 1.37 & 1.42 & 1.40 & 1.47 & 1.21 & 1.24 & 1.62 & 1.72 \\
\hline 300 & 0.13 & 0.188 & 25 & 1.09 & 1.11 & 1.17 & 1.20 & 1.52 & 1.59 & 1.60 & 1.70 & 1.31 & 1.36 & 1.94 & 2.08 \\
\hline 300 & 0.13 & 0.251 & 25 & 1.18 & 1.21 & 1.23 & 1.26 & 1.66 & 1.74 & 1.80 & 1.93 & 1.41 & 1.48 & 2.25 & 2.44 \\
\hline 300 & 0.17 & 0.125 & 25 & 0.97 & 0.99 & 1.12 & 1.14 & 1.39 & 1.44 & 1.40 & 1.47 & 1.22 & 1.26 & 1.62 & 1.72 \\
\hline 300 & 0.17 & 0.188 & 25 & 1.10 & 1.12 & 1.18 & 1.21 & 1.55 & 1.62 & 1.60 & 1.70 & 1.33 & 1.39 & 1.94 & 2.08 \\
\hline 300 & 0.17 & 0.251 & 25 & 1.19 & 1.22 & 1.25 & 1.28 & 1.70 & 1.78 & 1.80 & 1.93 & 1.45 & 1.52 & 2.25 & 2.44 \\
\hline 300 & 0.13 & 0.125 & 30 & 0.96 & 0.98 & 1.10 & 1.11 & 1.31 & 1.35 & 1.33 & 1.39 & 1.17 & 1.20 & 1.52 & 1.60 \\
\hline 300 & 0.13 & 0.188 & 30 & 1.08 & 1.10 & 1.14 & 1.17 & 1.44 & 1.50 & 1.50 & 1.58 & 1.26 & 1.30 & 1.78 & 1.90 \\
\hline 300 & 0.13 & 0.251 & 30 & 1.17 & 1.20 & 1.19 & 1.22 & 1.57 & 1.64 & 1.67 & 1.78 & 1.35 & 1.40 & 2.04 & 2.20 \\
\hline 300 & 0.17 & 0.125 & 30 & 0.96 & 0.98 & 1.10 & 1.12 & 1.33 & 1.38 & 1.33 & 1.39 & 1.19 & 1.22 & 1.52 & 1.60 \\
\hline 300 & 0.17 & 0.188 & 30 & 1.08 & 1.11 & 1.15 & 1.18 & 1.47 & 1.53 & 1.50 & 1.58 & 1.28 & 1.32 & 1.78 & 1.90 \\
\hline 300 & 0.17 & 0.251 & 30 & 1.18 & 1.20 & 1.20 & 1.24 & 1.60 & 1.68 & 1.67 & 1.78 & 1.37 & 1.43 & 2.04 & 2.20 \\
\hline 300 & 1.00 & 0.125 & 20 & 1.09 & 1.12 & 1.29 & 1.33 & 1.78 & 1.88 & 1.50 & 1.58 & 1.52 & 1.60 & 1.78 & 1.90 \\
\hline 300 & 1.00 & 0.188 & 20 & 1.26 & 1.29 & 1.43 & 1.50 & 2.06 & 2.18 & 1.75 & 1.87 & 1.78 & 1.90 & 2.17 & 2.35 \\
\hline 300 & 1.00 & 0.251 & 20 & 1.40 & 1.44 & 1.57 & 1.66 & 2.29 & 2.42 & 2.00 & 2.16 & 2.04 & 2.20 & 2.56 & 2.81 \\
\hline 300 & 1.00 & 0.125 & 25 & 1.07 & 1.10 & 1.23 & 1.26 & 1.66 & 1.74 & 1.40 & 1.47 & 1.42 & 1.48 & 1.62 & 1.72 \\
\hline 300 & 1.00 & 0.188 & 25 & 1.4 & 1.27 & 1.34 & 1.40 & 1.90 & 2.00 & 1.60 & 1.70 & 1.62 & 1.72 & 1.94 & 2.08 \\
\hline 300 & 1.00 & 0.251 & 25 & 1.37 & 1.41 & 1.46 & 1.53 & 2.11 & 2.23 & 1.80 & 1.93 & 1.83 & 1.96 & 2.25 & 2.44 \\
\hline 300 & 1.00 & 0.125 & 30 & 1.06 & 1.08 & 1.19 & 1.22 & 1.57 & 1.64 & 1.33 & 1.39 & 1.35 & 1.40 & 1.52 & 1.60 \\
\hline 300 & 1.00 & 0.188 & 30 & 1.22 & 1.25 & 1.29 & 1.33 & 1.78 & 1.88 & 1.50 & 1.58 & 1.52 & 1.60 & 1.78 & 1.90 \\
\hline 300 & 1.00 & 0.251 & 30 & 1.35 & 1.39 & 1.38 & 1.44 & 1.97 & 2.08 & 1.67 & 1.78 & 1.69 & 1.80 & 2.04 & 2.20 \\
\hline
\end{tabular}

parameters (concrete strength, fiber volume, corner radius of the of cross-section, etc.) and then applicable only to specific cases.

The reliability of the proposed procedure has been confirmed by a comparison between the values of strength increase deduced by the proposed procedures and those deduced from empirical or semi-empirical models given in the literature.

Finally, it is worth remarking that the proposed model, differently from what is usually done in the literature, relates the confinement effectiveness to a single parameter representative of the relative stiffness between the original concrete core and the reinforcement system.

\section{Compliance with ethical standards}

Conflict of interest The authors declare that they have no conflict of interest.

\section{References}

1. Campione G, Colajanni P, La Mendola L, Spinella N (2007) Ductility of R.C. members externally wrapped with frp sheets. J Compos Constr 11(3):279-290 
2. Xiao Y, Wu H (2000) Compressive behavior of concrete confined by carbon fiber composite jackets. J Mater Civil Eng 12(2):139-146

3. Pessiki S, Harries KA, Kestner JT, Sause R, Ricles JM (2001) Axial behavior of reinforced concrete columns confined with FRP jackets. ASCE J Compos Constr 5(4):237-245

4. Lam L, Teng JG (2003) Design-oriented stress-strain model for FRP-confined concrete. Constr Build Mater 17(6-7):471-489

5. Mirmiran A, ShahawyM Samaan M, El-Echary H (1998) Effect of column parameters on FRP confined concrete. ASCE J Compos Constr 2(4):175-185

6. Lam L, Teng JG (2004) Ultimate condition of fiber reinforced polymer-confined concrete. J Compos Constr 8(6):539-548

7. Wang L-M, Wu Y-F (2008) Effect of corner radius on the performance of CFRP-confined square concrete column: test. J Eng Struct 30(2):493-505

8. Lam L, Teng JG, Cheung CH, Xiao Y (2006) FRP-confined concrete under cyclic axial compression. Cement Concr Compos 28(10):948-958

9. Jiang T, Teng JG (2007) Analysis-oriented stress-strain models for FRP-confined concrete. Eng Struct 29(11):2968-2986

10. CNR-DT200 (2004) Guide for the design and construction of externally bonded FRP systems for strengthening existing structures (Materials, RC and PC Structures, masonry structures). CNR, National Research Council, Rome, Italy

11. ACI Committee 440 (2008) Guide for the design and construction of externally bonded FRP systems for strengthening concrete structures. ACI 440.2R-08, American Concrete Institute, Farmington Hills

12. Fédérationinternationale du Béton (fib). Externally bonded FRP reinforcement for RC structures. Bulletin no. 14, technical tep. Lausanne, Switzerland

13. Kurtz S, Balagru P (2001) Comparison of inorganic and organic matrices for strengthening of RC beams with carbon sheets. J Struct Eng ASCE 127(1):35-42

14. Wu HC, Teng J (2003) Concrete confined with fiber reinforced cement based thinsheet composites. In: Tan $\mathrm{KH}$ (ed) FRPRCS-6 fiber reinforced polymer reinforcement for concrete structures, vol 1. World Scientific Publishing Co., Singapore, pp 591-600

15. Triantafillou TC, Papanicolaou CG, PanagiotisZissimopoulos P, Laourdekis T (2006) Concrete confinement with textilereinforced mortar jackets. ACI Struct J 103(1):28-37

16. Bournas DA, Lontou PV, Papanicolaou CG, Triantafillou TC (2007) Textile-reinforced mortar versus fiber-reinforced polymer confinement in reinforced concrete columns. ACI Struct J 104(6):740-748

17. Ombres L (2007) Confinement effectiveness in concrete strengthened with fiber reinforced cement based composite jackets. FRPCS-8. Patras, Greece

18. y Basalo FJDC, Matta F, Nanni A (2012) Fiber reinforced cement-based composite system for concrete confinement. Constr Build Mater 32:55-65

19. Colajanni P, De Domenico F, Recupero A, Spinella A (2014) Concrete columns confined with fiber reinforced cementitious mortars: experimentation and modelling. Constr Build Mater 52:375-384

20. Trapko T (2013) Fiber reinforced cementitious matrix confined concrete elements. Mater Des 44:382-391
21. Rochette P, Labossiere $P$ (2000) Axial testing of rectangular column models confined with composites. ASCE J Compos Constr 4(3): 129-136

22. Yang X, Wei J, Nanni A, Dharani LR (2004) Shape effect onthe performance of carbon fiber reinforced polymer wraps. ASCE J Compos Constr 8(5):444-451

23. Mander JB, Priestley MJN, Park R (1988) Theoretical stress-strain model for confined concrete. ASCE J Struct Div 107(ST11):2227-2244

24. Pellegrino C, Modena C (2010) Analytical model for FRP confinement of concrete columns with and without internal steel reinforcement. J Compos Constr 14(6):693-705

25. Campione G, Miraglia N (2003) Strength and strain capacities of concrete compression members reinforced with FRP. Cem Concr Compos 25(1):31-41

26. Mostofinejad D, Moshiri N, Mortazavi N (2015) Effect of corner radius and aspect ratio on compressive behavior of rectangular concrete columns confined with CFRP. Mater Struct 48(1-2):107-122

27. Harries KA, Carey SA (2003) Shape and "gap" effects on the behavior of variably confined concrete. Cem Concr Res 33(6):881-890

28. Bullo S (2003) Experimental study of the effects of the ultimate strain of fiber reinforced plastic jackets on the behavior of confined concrete. In: Proceedings of the international conference "composites in construction". Cosenza; Italy, pp 465-70

29. Cui C (2009) Behaviour of normal and high strength concrete confined with fibre reinforced polymers (FRP). MSc Thesis, University of Toronto, pp 1-376

30. Colajanni P, Fossetti M, Macaluso G (2014) Effects of confinement level, cross-section shape and corner radius on the cyclic behavior of CFRCM confined concrete columns. Constr Build Mater 55:379-389

31. De Lorenzis L, Tepfers R (2003) Comparative study of models on confinement of concrete cylinders with fiber reinforced polymer composites. J. Compos Constr 7(3):219-237

32. Rousakis TC, Karabinis AI, Kiousis PD (2007) FRP-confined concrete members: axial compression experiments and plasticity modelling. Eng Struct 29(7):1343-1353

33. Wu Y-F, Wei Y-Y (2010) Effect of cross-sectional aspect ratio on the strength of CFRP-confined rectangular concrete columns. Eng Struct 32(1):32-45

34. Ombres L (2014) Concrete confinement with a cement based high strength composite material. Compos Struct 109:294-304

35. Matthys S, Taerwe L, Audenaert K (1999) Tests on axially loaded concrete columns confined by fiber reinforced polymer sheet wrapping. In: Proceedings of the fourth international symposium on fiber reinforced polymer reinforcement for reinforced concrete structures, ACI SP-188, Michigan, USA

36. Karabinis A, Rousakis TC (2001) Carbon FRP confined concrete elements under axial load. In: FRP composites in civil engineering conference, pp 309-316

37. Spoelstra MR, Monti G (1999) FRP-confined concrete model. ASCE J Compos Constr 3(3):143-152

38. Di Ludovico M, Prota A, Manfredi G (2010) Structural upgrade using basalt fibers for concrete confinement. ASCE J Compos Constr 14(5):541-552 